\title{
Splenectomy prolongs the effects of corticosteroids in mouse models of autoimmune hepatitis.
}

\section{AUTHOR(S):}

Maruoka, Ryutaro; Aoki, Nobuhiro; Kido, Masahiro; Iwamoto, Satoru; Nishiura, Hisayo; Ikeda, Aki; Chiba, Tsutomu; Watanabe, Norihiko

\section{CITATION:}

Maruoka, Ryutaro ...[et al]. Splenectomy prolongs the effects of corticosteroids in mouse models of autoimmune hepatitis.. Gastroenterology 2013, 145(1): 209-220.e9

\section{ISSUE DATE:}

2013-07

URL:

http://hdl.handle.net/2433/178171

\section{RIGHT:}

(c) 2013 AGA Institute. Published by Elsevier Inc.; この論文は出版社版で ありません。引用の際には出版社版をご確認ご利用ください。; This is not the published version. Please cite only the published version. 
Maruoka et al.

\section{Splenectomy Prolongs the Effects of Corticosteroids in Mouse Models of}

\section{Autoimmune Hepatitis}

Ryutaro Maruoka, ${ }^{1,2, \#}$, Nobuhiro Aoki ${ }^{1,2, \#}$, Masahiro Kido ${ }^{1,2}$, Satoru Iwamoto ${ }^{1,2}$, Hisayo Nishiura $^{1,2}$, Aki Ikeda ${ }^{1,2}$, Tsutomu Chiba ${ }^{2}$, and Norihiko Watanabe ${ }^{1,2, *}$

${ }^{1}$ Center for Innovation in Immunoregulative Technology and Therapeutics, and ${ }^{2}$ Department of Gastroenterology and Hepatology, Graduate School of Medicine, Kyoto University, Kyoto 606-8501, Japan

\# These authors contributed equally to this work.

* Correspondence: Norihiko Watanabe, Tel:+81-75-751-4319, Fax:+81-75-751-4303, E-mail: norihiko@kuhp.kyoto-u.ac.jp

Running title: Therapeutic efficacy of splenectomy for AIH

Abbreviations: AIH, autoimmune hepatitis; ALT, alanine aminotransferase; ANA, anti-nuclear antibody; AST, aspartate aminotransferase; autoAbs, autoantibodies; DEX, dexamethasone; ELISA, enzyme-linked immunosorbent assay; GC, germinal center; Ig, immunoglobulin; NTx, neonatal thymectomy; PBS, phosphate-buffered saline; NTx-PD-1 ${ }^{-1-}$ mice, PD-1-deficient mice thymectomized three days after birth; PD-1, programmed cell death 1; PNA, peanut agglutinin; $\mathrm{T}_{\mathrm{FH}}$, follicular helper $\mathrm{T}$; Tregs, regulatory T cells 
Maruoka et al.

\section{Abstract}

BACKGROUD \& AIMS: Patients with autoimmune hepatitis (AIH) initially respond to corticosteroids but often relapse after treatment is withdrawn. BALB/c mice with disruption of programmed cell death-1 ( $P D-1^{-/-}$mice) given thymectomies 3 days after birth develop a dysregulated immne system, greatly reduced Foxp $3^{+}$regulatory $\mathrm{T}$ cells, and undergo fulminant hepatic failure resembling acute-onset AIH in humans. We examined whether splenectomy overcomes corticosteroid insufficiency and reduces the severity of AIH in these mice. We also developed a mouse model of chronic AIH to investigate the effects of splenectomy.

METHODS: After thymectomy, BALB/c- $P D-1^{-/-}$mice were given dexamethasone before or after induction of $\mathrm{AIH}$; splenectomies were performed in mice that had and had not been given dexamethasone. Neonatal C57BL/6-PD-1/- mice were given thymectomies to create a model of chronic AIH.

RESULTS: Injection of dexamethasone before or after induction of $\mathrm{AIH}$ prevented development of fatal AIH in BALB/c-PD-1 ${ }^{-/-}$mice. However, injection after AIH induction did not suppress splenic production of follicular helper $\mathrm{T}$ cells, and discontinuing dexamethasone led to relapse of AIH. However, splenectomy, even without dexamethasone, prevented AIH. Neonatal C57BL/6-PD-1/- mice given thymectomies developed chronic hepatitis with fibrosis, and hyper- $\gamma$-globulinemia and produced anti-nuclear antibodies; AIH was found to be induced in the spleen. Splenectomy reduced liver inflammation in these mice and in BALB/C- $P D-1^{-/-}$mice with AIH.

CONCLUSIONS: Disruption of PD-1 and thymectomy, a model of AIH, cause the same disruptions in immune regulation but produce different phenotypes in BALB/c vs C57BL/6 mice. Splenectomy overcomes corticosteroid insufficiency in the mice and prolongs the effects of dexamethasone.

Keywords: autoimmunity, ANA, necrosis, T cell response, Treg 
Maruoka et al.

\section{Introduction}

Corticosteroid administration is the first-line therapy for patients with autoimmune hepatitis (AIH). The majority initially respond well to corticosteroids, alone or in combination with azathioprine. ${ }^{1-4}$ After initial remission, maintenance therapy is continued for years. However, long-term treatment is discontinued in $13 \%$ of AIH patients because of drug-related side effects. ${ }^{5,6}$ Half of AIH patients with remission relapse within 6 months after corticosteroid withdrawal, and multiple relapses are associated with a poor prognosis. ${ }^{7,8}$ Even when liver inflammation disappears completely, $13 \%$ of those patients eventually relapse. ${ }^{9}$ In addition to the difficulty in sustaining remission, a recent study showed that the long-term mortality of AIH patients due to liver disease is greater than that of the general population. ${ }^{10}$ Notably, in Europe and the United States, AIH patients account for $4 \%$ of liver transplants. ${ }^{4}$ To find clues to overcoming the therapeutic insufficiency of corticosteroids, preclinical animal models for detail examination are needed.

AIH is characterized by mononuclear-cell infiltration in the liver and elevated gammaglobulins as well as by the production of a variety of characteristic autoantibodies (autoAbs), including anti-nuclear antibodies (ANA) ${ }^{1-3}$ Liver-infiltrating $\mathrm{T}$ cells are considered the primary disease mediators of inflammatory liver damage, and circulating autoAbs are diagnostic hallmarks. ${ }^{1-3}$ However, in AIH patients, clinical manifestations are varied, ranging from non-symptomatic mild chronic hepatitis to fulminant hepatic failure. ${ }^{1-3}$ It is unclear whether the varied clinical manifestations of AIH result from the same immune dysregulation.

Recently, we developed the first mouse model of spontaneous AIH. ${ }^{11,12}$ In programmed cell death 1-deficient $\left(P D-1^{-/}\right)$mice on the BALB/c background with neonatal thymectomy (NTx) three days after birth, immune dysregulation by a concurrent loss of naturally arising $\mathrm{Foxp}^{+}$regulatory $\mathrm{T}$ cells (Tregs) and PD-1-mediated signaling induced fatal AIH resembling acute-onset $\mathrm{AIH}$, presenting in humans as fulminant hepatic failure. ${ }^{11}$ The development of fatal AIH was initiated at two weeks of age, and extensive destruction of the liver parenchyma resulted in most mice dying by four weeks. Fatal AIH in BALB/c-NTx- $P D-1^{-/-}$mice was characterized by $\mathrm{CD}^{+}$and $\mathrm{CD}^{+}$T-cell infiltration with massive lobular necrosis in the liver, hyper-gammaglobulinemia, and production of ANA. ${ }^{11,12}$ In BALB/c-NTx-PD-1 ${ }^{-/-}$mice, fatal AIH was initiated at two weeks by splenic follicular helper $T\left(T_{F H}\right)$ cells, powerfully assisting B cells in forming germinal centers (GCs). ${ }^{13}$ In addition, these $\mathrm{T}_{\mathrm{FH}}$ cells in the spleen directly migrated into the liver via the CCR6-CCL20 axis, triggering 
Maruoka et al.

the induction of AIH. ${ }^{12}$ However, the development of mouse models of chronic hepatitis similar to the human disease remained an important challenge.

In the present study, using our mouse model of fatal AIH, we examined the effects of administering dexamethasone (DEX) versus splenectomy on the development or progression of AIH. In addition, we developed a new model of chronic AIH. NTx-PD-1/- mice on the different genetic background C57BL/6 developed chronic hepatitis with fibrosis, hyper-gammaglobulinemia, and the production of ANA, allowing us to examine the effects of administering DEX versus splenectomy. 
Maruoka et al.

\section{Materials and Methods}

All protocols for mice, administration of DEX in vivo, histological and immunohistological analysis, flow cytometry analysis, isolation of lymphocytes, ELISA, adoptive transfer, and histological activity index (HAI) scores, $^{14}$ are detailed in Supplementary Methods.

\section{Statistical analysis}

The data are presented as the mean values \pm SD. Statistical analysis was performed by Student's $t$-test for unpaired data to compare the values between the two groups, and variance was analyzed with the Tukey-Kramer test for multiple comparisons. Survival rates were estimated by the Kaplan-Meier method and compared with the log-rank test. $P$-values below .05 were considered significant. 
Maruoka et al.

\section{Results}

DEX prevents the development of fatal AIH in $B A L B / C-N T X-P D-1^{-/}$mice

First, to determine whether corticosteroid treatment prevents $\mathrm{AIH}$ in $\mathrm{BALB} / \mathrm{c}-\mathrm{NTx}-P D-1^{-/-}$mice, these mice at one day after thymectomy were intraperitoneally injected every other day with DEX diluted in PBS or with PBS alone (Figure 1A). After 13 injections, mice at four weeks of age showed that DEX injections suppressed severe infiltration of mononuclear cells as well as massive destruction of the liver parenchyma with decreased serum concentrations of aspartate aminotransferase (AST) and alanine aminotransferase (ALT), resulting in a significantly higher survival rate compared with control PBS injections (Figure $1 A, B$ and Supplementary Figure $1 A$ ). These data indicate that DEX prevents fatal AIH in these mice.

Therapeutic administration of $\mathrm{DEX}$ induces regression of inflammation in the liver and significantly increases survival in $B A L B / C-N T X-P D-1^{-/}$mice

Next, we examined whether corticosteroids might have the same therapeutic efficacy for AIH in BALB/c-NTx-PD-1 ${ }^{-/-}$mice as for human AIH. Because AIH induction was started by 14 days of age in most of the mice, ${ }^{11,12}$ intraperitoneal injections of DEX were started at 17 days (Figure 1C). After 6 injections every other day, at four weeks therapeutic injections of DEX suppressed $\mathrm{AIH}$, inducing significantly greater survival (Figure $1 C, D$ and Supplementary Figure $1 B$ ). These data suggest that similar to human $\mathrm{AIH}$, treatment with corticosteroids after AIH induction is therapeutic for BALB/c-NTx-PD-1 ${ }^{-/-}$mice.

\section{Administration of DEX reduces serum IgG levels and ANA production in} BALB/C-NTX-PD-1 ${ }^{-/}$mice

Using ELISA and immunofluorescence assay, we next examined whether IgG or ANA levels were affected by preventive or therapeutic injections of DEX. Although serum IgM levels were not changed by DEX treatments, serum IgG levels were significantly reduced by both preventive and therapeutic injections of DEX (Figures $1 E$ ). These data are consistent with the finding in AIH patients, in which reduced serum AST after corticosteroid therapy is generally associated with reduced levels of $\gamma$-globulin and of IgG. In addition, ANA levels were reduced significantly in mice with preventive injections and slightly but not significantly in mice receiving therapeutic injections of DEX (Figures $1 E$ and $1 F$ ). 
Maruoka et al.

Therapeutic administration of $\mathrm{DEX}$ reduces the size of the spleen but does not completely regress GC-forming $B$ cell follicles and $T_{F H}$ cells in the spleen of $B A L B / C-N T X-P D-1^{-/-}$mice

As reported previously, ${ }^{12}$ the spleens of BALB/c-NTx-PD-1 ${ }^{-/-}$mice at 4 weeks of age were enlarged, showing multiple $\mathrm{PNA}^{+} \mathrm{GC}$-forming $\mathrm{B}$ cell follicles. DEX treatments significantly reduced spleen size and weight, suggesting that they affect the induction site of AIH development (Figures $2 A$, and Supplementary Figure $2 A$ and $2 B$ ). However, therapeutic but not preventive DEX injections allowed persistence of multiple B-cell follicles in the spleen (Figure $2 B$ upper panels) and of $\mathrm{CD}^{+} \mathrm{T}_{\mathrm{FH}}$ cells as well as $\mathrm{PNA}^{+} \mathrm{GC}$ formation in the $\mathrm{B} 220^{+} \mathrm{B}$-cell follicles (Figure $2 \mathrm{~B}$ middle and lower panels) in the spleens of BALB/c-NTx-PD-1 ${ }^{-/-}$mice aged 4 weeks. In addition, flow cytometric analysis of splenic $\mathrm{CD}^{+}{ }^{+}$T cells demonstrated that these cells in mice therapeutically treated with DEX contained $\mathrm{ICOS}^{+} \mathrm{CXCR}^{+} \mathrm{T}_{\mathrm{FH}}$ cells at levels similar to controlled mice treated with PBS. In contrast, $\mathrm{ICOS}^{+} \mathrm{CXCR}^{+} \mathrm{T}_{\mathrm{FH}}$ cells in $\mathrm{CD} 4^{+} \mathrm{T}$-cell populations were reduced in mice preventively treated with DEX (Figure 2C). Although DEX injections may affect immune cells other than $\mathrm{T}$ cells in the spleen, therapeutic injections of DEX allowed $\mathrm{T}_{\mathrm{FH}}$ cells to persist.

Corticosteroids directly induce apoptosis of lymphocytes, whereas Tregs expressing higher levels of glucocorticoid receptors are reported to be resistant to DEX-mediated apoptosis, probably due to high expression of $\mathrm{Bcl}-2 .{ }^{15-17} \mathrm{We}$ next examined whether splenic $\mathrm{CD}^{+} \mathrm{T}$ cells containing $\mathrm{T}_{\mathrm{FH}}$ cells are more resistant to DEX-mediated apoptosis than other T cells. $\mathrm{CD} 4^{+}$and $\mathrm{CD}^{+} \mathrm{T}$ cells were purified from the spleen of BALB/C-NTX-PD-1 ${ }^{-/-}$mice therapeutically treated with DEX and cultured with various concentrations of DEX (Figure $2 D$ ). After three days of culture, 7-AADnon-apoptotic cells were significantly and dose-dependently reduced in the $\mathrm{CD}^{+}{ }^{+} \mathrm{T}$-cell population cultured with DEX. In contrast, 7-AAD ${ }^{-}$non-apoptotic cells were not altered in the $\mathrm{CD}^{+}{ }^{\mathrm{T}}$-cell population cultured with DEX (Figure $2 D$ ). These data suggest that in $\mathrm{BALB} / \mathrm{c}-\mathrm{NTX}-P D-1^{-/-}$mice, splenic $\mathrm{CD} 4^{+} \mathrm{T}$ cells containing $\mathrm{T}_{\mathrm{FH}}$ cells are more resistant to DEX-mediated apoptosis than effector $\mathrm{CD}^{+} \mathrm{T}$ cells.

\section{Residual splenic $\mathrm{CD}^{+}$cells after therapeutic injections of DEX can induce hepatitis in RAG2 $2^{-/-}$mice.}

Next, we investigated whether residual splenic $\mathrm{CD} 4^{+}$cells after therapeutic DEX injections can induce AIH. Total splenocytes, purified splenic CD4 ${ }^{+}$cells, or $\mathrm{CD}^{+}$T-cell depleted splenocytes were transferred from BALB/c-NTx- $P D-1^{-/-}$mice therapeutically treated with DEX at three weeks into $\mathrm{T}$ - and B-cell-deficient 
Maruoka et al.

$\mathrm{BALB} / \mathrm{c}-R A G 2^{-/-}$mice. Three weeks later, we found that transferring total splenocytes from mice therapeutically treated with DEX induced mononuclear cell infiltrations in the liver of recipient mice and significantly increased serum levels of AST and ALT to levels similar to untreated mice (Figure $2 E$ and Supplementary Figure 2C). Notably, purified splenic $\mathrm{CD}^{+}{ }^{+} \mathrm{T}$ cells but not $\mathrm{CD}^{+}{ }^{+}$T-cell-depleted splenocytes also induced hepatitis (Figure $2 F$ and Supplementary Figure $2 D$ ). Taken together, these data suggest that residual splenic $\mathrm{CD} 4^{+}$cells after DEX injection trigger the recurrence of $\mathrm{AIH}$ in mice.

Ending DEX therapy induces fatal hepatitis, whereas extending it allows residual GC-forming $B$ cell follicles in the spleen of BALB/C-NTX-PD-1 ${ }^{-/-}$mice

To examine whether stopping DEX injections results in relapse, DEX administration was ended at 28 days of age after 6 therapeutic injections, or continued until 40 days of age in control mice (Figure 3A). Continuous DEX treatment maintained suppressed inflammatory infiltration in the liver and hepatic damage in association with a high survival rate (Figure $3 A, 3 B$ and Supplementary Figure 3), but GC-forming B cell follicles were still present in the spleens (Figure $3 B$ ). In contrast, stopping DEX at 28 days resulted in the recurrence of hepatitis at 40 days, accompanied by reduced survival rates (Figure $3 A, 3 B$, and Supplementary Figure 3 ). These data suggest a limitation in the therapeutic use of corticosteroids for resolving the dysregulation of $\mathrm{T}_{\mathrm{FH}}$ cells in the spleen, the AIH-induction site, in BALB/c-NTx-PD-1/-- mice.

\section{Splenectomy after the development of AIH suppresses progression to fatal} AIH in BALB/C-NTX-PD-1/- mice

Previously we reported that neonatal splenectomy has a preventive effect on AIH development in BALB/c-NTx-PD-1 ${ }^{-/-}$mice. ${ }^{12}$ In this study, we evaluated splenectomy as a therapeutic option. Similar to the neonatal procedure, splenectomy at 7 or 10 days of age before AIH induction suppressed the development of fatal hepatitis (Figure 3C). Importantly, we found that splenectomy at 17 or 21 days of age after AIH development also suppressed liver inflammation and improved survival, sustaining remission until 45 days (Figure 3C-E).

In addition, splenectomy at 21 days of age following DEX therapy suppressed liver inflammation in association with a high survival rate at 40 days of age, sustaining remission until 60 days (Figure $3 F$ ). Moreover, when we performed splenectomy at four weeks of age following DEX therapy, liver inflammation was suppressed at 56 days of 
Maruoka et al.

age (Supplementary Figure 4). These data suggest that splenectomy induces prolonged remission of $\mathrm{AIH}$ in $\mathrm{BALB} / \mathrm{c}-\mathrm{NTX}-P D-1^{-/-}$mice.

\section{AIH developed in C57BL/6-NTX-PD-1 ${ }^{-/}$mice shares characteristic components of chronic hepatitis in AIH patients}

In AIH patients, clinical manifestations of AIH are varied, and the disease manifestation has been associated with specific alleles of the major histocompatibility complex. $^{1-3,18,19}$ To test whether different genetic backgrounds induce milder disease manifestation in NTx-PD-1/- mice, we performed NTx in $P D-1^{-/-}$mice that had been backcrossed onto the C57BL/6 background for 11 generations. ${ }^{20}$

In two-week-old BALB/c-NTx-PD-1 ${ }^{-/}$mice with hepatitis, pathogenic splenic $\mathrm{T}_{\mathrm{FH}}$ cells were preferentially localized within $\mathrm{B} 220^{+}$B-cell follicles and autonomously developed $\mathrm{PNA}^{+}$GCs (Supplementary Figure 5). ${ }^{12}$ In contrast, although in C57BL/6-NTx-PD-1 $1^{-/-}$mice of the same age, splenic CD4 ${ }^{+} \mathrm{T}$ cells were located within the follicles, these B-cell follicles did not develop PNA ${ }^{+}$GCs (Supplementary Figure 5 and Figure 4A). Interestingly, flow cytometric analysis demonstrated that in parallel with the increase of $\mathrm{ICOS}^{+} \mathrm{CD}^{+} \mathrm{T}$ cells including $\mathrm{CXCR}^{+} \mathrm{T}_{\mathrm{FH}}$ cells in C57BL/6-NTx- $P D-1^{-/-}$mice at 6 weeks of age (Supplementary Figure $6 A$ ), $\mathrm{PNA}^{+}$GCs were autonomously developed (Figure $4 A$ ), and B220 ${ }^{+} \mathrm{B}$ cells expressed Fas and GL7 (Figure $4 B$ ), hallmarks of GC B cells. Importantly, livers in C57BL/6-NTx-PD- $1^{-/-}$mice as young as 4 weeks showed mononuclear cell infiltrations, predominantly in the portal area. The infiltration was sustained in older mice, resulting in bridging fibrosis (Figure $4 C, 4 D$ vii, viii, and Supplementary Figure 6B). Histological examination of the liver in eight-week-old C57BL/6-NTx-PD- $1^{-/}$mice showed interface hepatitis with periportal necrosis without bile duct destruction (Figure $4 D$ i-iii), intralobular degeneration (Figure $4 D$ iv), or portal inflammation (Figure $4 D$ v), as well as fibrosis (Figure $4 D$ vi). These findings are associated with an increased HAI score and increased serum levels of AST and ALT (Figure 4E and Supplementary Figure 6C ).

In addition, C57BL/6-NTx-PD-1 $1^{-/-}$mice older than 4 weeks showed hyper-gammaglobulinemia and significantly increased production of ANAs as detected by ELISA and immunofluorescence assay (Figure 5A-C). All C57BL/6-NTx-PD-1 ${ }^{-/}$ mice older than 8 weeks developed $\mathrm{AIH}$, whereas some of the AIH-bearing mice, to a lesser frequency, manifested other organ-specific autoimmunity such as sialadenitis, as do patients with chronic AIH (Figure $5 D$ and Supplementary Table 1 ).$^{1-3}$ These data suggest that human chronic AIH and AIH developed in C57BL/6-NTx-PD-1/- mice share characteristic components of the disease. 
Chronic hepatitis developed in C57BL/6-NTX-PD-1 $1^{-/-}$mice is organ-specific autoimmunity induced by $\mathrm{CD}^{+} \mathrm{T}$ cells.

In six-week-old C57BL/6-NTx-PD-1 ${ }^{-/-}$mice, flow cytometric analysis demonstrated that $\mathrm{CD}^{+} \mathrm{T}$ cells predominantly infiltrated the liver. These cells were mainly $\mathrm{CD}^{+} \mathrm{T}$ cells and, to a lesser extent, $\mathrm{CD}^{+} \mathrm{T}$ cells, as described for BALB/c-NTx-PD-1 ${ }^{-/-}$mice (Figure $5 E$ and $5 F$ ). ${ }^{11}$ These results were further confirmed by immunohistology (Figure $6 A$ ). In BALB/c-NTx- $P D-1^{-/-}$mice, $\mathrm{CD} 4^{+} \mathrm{T}$ cells in the enlarged spleen directly triggered $\mathrm{AIH}$ development. ${ }^{12}$ Although adult C57BL/6-NTx-PD-1 $1^{-/}$mice did not show obvious splenomegaly (Figure $6 B$ and Supplementary Figure 7), transfer of splenic $\mathrm{CD}^{+} \mathrm{T}$ cells from AIH-bearing C57BL/6-NTx- $P D-1^{-/-}$mice at eight weeks of age into T- and B-cell-deficient $R A G 2^{-/-}$ mice induced hepatitis in recipient mice at three weeks after transfer (Figure 6C). These data suggest that splenic $\mathrm{CD}^{+}{ }^{+} \mathrm{T}$ cells directly trigger $\mathrm{AIH}$ in this chronic model.

In addition, using ELISA sets for cytokines, we found that serum cytokine levels of TNF- $\alpha$ but not IFN- $\gamma$ increased in six-week-old C57BL/6-NTx-PD-1/- mice (Figure 6D). Furthermore, when we transferred splenic $\mathrm{CD}^{+} \mathrm{T}$ cells from AIH-bearing C57BL/6-NTx- $P D-1^{-/-}$mice as described above (Figure 6C), transferred CD4 ${ }^{+} \mathrm{T}$ cells induced not only hepatitis but also elevated serum levels of TNF- $\alpha$ in recipient mice (Figure 6E). Because TNF- $\alpha$ directly and indirectly induces cell death of hepatocytes, ${ }^{21}$ TNF- $\alpha$ may be involved in hepatocytic damage in C57BL/6-NTx-PD-1/- mice.

Analysis of the TCR repertoire in several autoimmune diseases has shown antigen-driven clonal expansion of autoreactive $\mathrm{T}$ cells in the target organs. ${ }^{22-26}$ In patients with $\mathrm{AIH}$, analyses of the TCR repertoire have shown skewing of $\mathrm{V}_{\beta}$ chain usage, suggesting oligoclonal expansion of liver-infiltrating $\mathrm{T}$ cells. ${ }^{27,}{ }^{28}$ In addition, liver-infiltrating LKM-1-specific CD4+ T cell clones have shown a restricted TCR $\mathrm{V}_{\beta}$ repertoire. ${ }^{29}$ To determine the clonality of infiltrating $\mathrm{CD}^{+}{ }^{+} \mathrm{T}$ cells in the liver, we used flow cytometry to examine the TCR $\mathrm{V}_{\beta}$ usage of hepatic CD4 ${ }^{+} \mathrm{T}$ cells. Broad TCR $\mathrm{V}_{\beta}$ usages were equivalent to hepatic $\mathrm{CD}^{+} \mathrm{T}$ cells in wild type mice and $P D-1^{-/-}$mice without NTx (Figure 6F upper and middle panels). In contrast, in six-week-old C57BL/6-NTx- $P D-1^{-/-}$mice, effector $\mathrm{T}$ cells infiltrated into the liver showed clonal expansion (Figure $6 F$ lower left). Interestingly, in the case of fatal hepatitis in three-week-old BALB/c-NTx-PD-1 ${ }^{-/}$mice, effector $\mathrm{T}$ cells infiltrated into the liver showed more abundant clonal expansion, probably affecting severity of inflammation (Figure $6 F$ lower right). These data suggest that mono- or origo-clonal expansion of infiltrating effector $\mathrm{CD} 4^{+} \mathrm{T}$ cells in the liver may be relevant to the proliferation of 
Maruoka et al.

autoreactive $\mathrm{CD}^{+} \mathrm{T}$ cells induced by autoantigen-presenting dendritic cells in the spleen.

In addition, in C57BL/6-NTx-PD-1 $1^{-/-}$mice, we found that infiltrates in the liver were less likely to contain Tregs (Supplementary Figure 8A). Previously, we demonstrated that in BALB/c-NTx- $P D-1^{-/-}$mice, the transfer of Tregs could not suppress progression of fatal hepatitis after the induction of $\mathrm{AIH} .{ }^{11}$ However, when Tregs isolated from splenocytes of adult C57BL/6-PD-1 ${ }^{-/}$mice (Supplementary Figure $8 B$ ) were transferred into four-week-old C57BL/6-NTx- $P D-1^{-/-}$mice, the transfer suppressed chronic AIH (Supplementary Figure $8 C-E$ ). In humans, Tregs in peripheral blood have the same suppressive activity as Tregs isolated from the spleen in mice. ${ }^{30-32}$ Thus, Tregs isolated from peripheral blood and expanded ex vivo might be able to suppress human AIH.

The spleen is the induction site of $A I H$ in $C 57 B L / 6-N T x-P D-1^{-/-}$mice, and splenectomy suppresses chronic AIH similar to fulminant $\mathrm{AIH}$.

C57BL/6-NTx-PD-1 ${ }^{-/-}$mice at 4 weeks showed mononuclear cell infiltrations in the liver and increased serum levels of AST and ALT (Figure $4 C$ and 7A). To examine whether corticosteroids have therapeutic efficacy for chronic AIH in C57BL/6-NTx-PD-1 $1^{-/-}$mice as in human AIH, intraperitoneal injections of DEX were started at 4 weeks (Figure 7B). After 14 injections every other day until eight weeks of age, therapeutic injections of DEX suppressed AIH (Figure $7 B$ and Supplementary Figure 9).

As in BALB/c-NTx-PD-1 ${ }^{-/-}$mice, neonatal splenectomy also suppressed $\mathrm{AIH}$ in C57BL/6-NTx-PD-1 ${ }^{-/-}$mice (Figure $7 C$, Supplementary Figure $10 A$ and $10 B$ ), suggesting that the spleen is the induction site for chronic $\mathrm{AIH}$ development in C57BL/6-NTX-PD-1/- mice.

Finally, we evaluated splenectomy as a therapeutic option, performing splenectomies on four-week-old mice. Similar to the neonatal procedure, splenectomy at four weeks suppressed AIH in eight-week-old C57BL/6-NTx- $P D-1^{-/-}$mice (Figure $7 D$, Supplementary Figure $10 C$ and $10 D$ ). Notably, splenectomy neither induced fatal infection nor decreased the survival rate (Supplementary Table 2), whereas splenectomy at 12 weeks suppressed $\mathrm{AIH}$, sustaining remission until 20 weeks of age (Figure $7 E$ and $7 F$ ). Thus, these data suggest that splenectomy has therapeutic efficacy for chronic AIH similar to fulminant AIH. 
Maruoka et al.

\section{Discussion}

Using the AIH models, we here examined the effects of administering dexamethasone (DEX) to find clues to overcoming therapeutic insufficiency of corticosteroids for $\mathrm{AIH}$. We demonstrated that $\mathrm{T}_{\mathrm{FH}}$ cells in the spleen are responsible not only for the development of AIH but also for relapse after corticosteroid treatment. In $\mathrm{BALB} / \mathrm{c}-\mathrm{NTX}-P D-1^{-/}$mice, the spleen is the induction site for fatal $\mathrm{AIH}$, and responsible $\mathrm{T}_{\mathrm{FH}}$ cells are dysregulated in the spleen under the concurrent loss of Tregs and PD-1-mediated signaling. CCR6-CCL20 axis-dependent migration of these T cells triggers $\mathrm{AIH} .^{12}$ In addition, fatal progression is mediated by further differentiation of Th1-type effector $\mathrm{T}$ cells from $\mathrm{T}_{\mathrm{FH}}$ cells in the spleen, and a specific chemokine-dependent migration of those $\mathrm{T}$ cells is crucial for fatal progression (unpublished data). We demonstrated that injections of DEX are therapeutic for fatal AIH in this model, whereas $\mathrm{T}_{\mathrm{FH}}$ cells still exist in the spleen, even after continuous DEX administration: stopping the treatment resulted in fatal AIH. In addition, residual splenic $\mathrm{CD}^{+} \mathrm{T}$ cells after therapeutic injections of $\mathrm{DEX}$ were more resistant to DEX-mediated apoptosis, and transfer of these residual splenic $\mathrm{CD} 4^{+}$cells induced the development of hepatitis in the recipient $R A G 2^{-/-}$mice. From these data, we concluded that in the mouse model of $\mathrm{AIH}$, corticosteroid treatment has the drawback of allowing dysregulated $\mathrm{T}_{\mathrm{FH}}$ cells to remain in the spleen.

We described another AIH model in which C57BL/6-NTx-PD-1 ${ }^{-/-}$mice developed chronic hepatitis with fibrosis, hyper-gammaglobulinemia, and the production of ANA. Notably, dysregulated $\mathrm{T}_{\mathrm{FH}}$ cells were generated in the spleen, neonatal splenectomy suppressed chronic $\mathrm{AIH}$, and transfer of splenic CD4 ${ }^{+} \mathrm{T}$ cells induced hepatitis in the recipient $R A G 2^{-/-}$mice. These results indicate that in mice, the same induction mechanisms are involved in AIH development, with manifestations ranging from acute onset to chronic. In humans, it is unknown at present whether the spleen is the induction site of AIH or whether $\mathrm{T}_{\mathrm{FH}}$ cells are responsible for the development of $\mathrm{AIH}$, though splenomegaly is a common clinical finding in patients with active AIH. ${ }^{1-3}$ Therefore, it is important to know whether similar mechanisms are involved in the relapse of human AIH after corticosteroid withdrawal.

In our previous and present studies, we showed that splenectomy, either neonatal or at 7 or 10 days of age before the induction of $\mathrm{AIH}$, suppressed $\mathrm{AIH}$ presenting as fulminant hepatic failure in BALB/c-NTx-PD- $1^{-/-}$mice. ${ }^{12}$ In this study, we revealed that neonatal splenectomy also suppressed the development of chronic AIH in C57BL/6-NTx- $P D-1^{-/-}$mice. Because patients with severe AIH have a high potential for 
Maruoka et al.

recurrence after liver transplantation, leading to a greater probability of graft loss, splenectomy might well prevent such recurrence.

Interestingly, we further observed in this study that splenectomy after the development of AIH suppressed liver inflammation with manifestations ranging from acute onset to chronic. In the acute AIH model, splenectomy alone suppressed liver inflammation and sustained remission for 4 weeks. In addition, splenectomy following DEX therapy suppressed AIH and extended remission beyond 4 weeks. Moreover, in the chronic AIH model, splenectomy at 12 weeks of age suppressed AIH, sustaining remission until 20 weeks. It is well known that $\mathrm{AIH}$ patients in remission after withdrawal of corticosteroids are likely to relapse and that multiple relapses are associated with poor prognosis. ${ }^{7,8}$ Therefore, it is of interest to determine whether, in some patients with $\mathrm{AIH}$, splenectomy might be considered though this will need to be very carefully assessed given the concerns related to splenectomy.

In conclusion, we demonstrated that although corticosteroid treatment has therapeutic efficacy for $\mathrm{AIH}$ in mice, it allows residual splenic dysregulated $\mathrm{T}_{\mathrm{FH}}$ cells to remain after the treatment, which appear to be responsible for relapse. In addition, we found that splenectomy overcomes this insufficiency, inducing prolonged remission of AIH. These data may prove useful in obtaining complete remission in human AIH. 
Maruoka et al.

None of the authors has any financial conflict of interest to disclose in relation to the submission.

Grant Support: The Center for Innovation in Immunoregulative Technology and Therapeutics is supported in part by the Special Coordination Funds for Promoting Science and Technology of the Japanese Government and in part by Astellas Pharma Inc. in the Formation of Innovation Center for Fusion of Advanced Technologies Program. This work is partially supported by Grants-in-aid for Scientific Research 21229009, and 23590973 from Japan Society for the Promotion of Science (JSPS), a Health and Labour Sciences Research Grant for Research on Intractable Diseases, and Research on Hepatitis from the Ministry of Health, Labour and Welfare, Japan, Grants-in-Aid for Research by The Kato Memorial Trust for Nambyo Research, and The Waksman Foundation of Japan.

Acknowledgments: We thank Dr. Taku Okazaki and Tasuku Honjo for providing of PD-1 deficient mice; Dr. Dovie Wylie for assistance in preparation of the manuscript; Ms. Chigusa Tanaka for excellent technical assistance; Drs. Shuh Narumiya, Nagahiro Minato, Shimon Sakaguchi, Takeshi Watanabe, and Ichiro Aramori for critical discussion and suggestions. 
Maruoka et al.

\section{References}

1. Krawitt EL. Autoimmune hepatitis. N Engl J Med 2006;354:54-66.

2. Manns MP, Czaja AJ, Gorham JD, et al. Diagnosis and management of autoimmune hepatitis. Hepatology 2010;51:2193-2213.

3. Czaja AJ, Manns MP. Advances in the diagnosis, pathogenesis, and management of autoimmune hepatitis. Gastroenterology 2010;139:58-72.

4. Manns MP. Autoimmune hepatitis: the dilemma of rare diseases. Gastroenterology 2011;140:1874-1876.

5. Czaja AJ, Davis GL, Ludwig J, et al. Complete resolution of inflammatory activity following corticosteroid treatment of HBsAg-negative chronic active hepatitis. Hepatology 1984;4:622-627.

6. Czaja AJ. Safety issues in the management of autoimmune hepatitis. Expert Opin Drug Saf 2008;7:319-333.

7. Czaja AJ, Ammon HV, Summerskill WH. Clinical features and prognosis of severe chronic active liver disease (CALD) after corticosteroid-induced remission. Gastroenterology 1980;78:518-523.

8. Montano-Loza AJ, Carpenter HA, Czaja AJ. Consequences of treatment withdrawal in type 1 autoimmune hepatitis. Liver Int 2007;27:507-515.

9. Montano-Loza AJ, Carpenter HA, Czaja AJ. Improving the end point of corticosteroid therapy in type 1 autoimmune hepatitis to reduce the frequency of relapse. Am J Gastroenterol 2007;102:1005-1012.

10. Hoeroldt B, McFarlane E, Dube A, et al. Long-term outcomes of patients with autoimmune hepatitis managed at a nontransplant center. Gastroenterology 2011;140:1980-1989.

11. Kido M, Watanabe N, Okazaki T, et al. Fatal autoimmune hepatitis induced by concurrent loss of naturally arising regulatory $\mathrm{T}$ cells and PD-1-mediated signaling. Gastroenterology 2008;135:1333-1343.

12. Aoki N, Kido M, Iwamoto S, et al. Dysregulated generation of follicular helper T cells in the spleen triggers fatal autoimmune hepatitis in mice. Gastroenterology 2011;140:1322-1333.

13. King $\mathrm{C}$. New insights into the differentiation and function of $\mathrm{T}$ follicular helper cells. Nat Rev Immunol 2009;9:757-766.

14. Knodell RG, Ishak KG, Black WC, et al. Formulation and application of a numerical scoring system for assessing histoloical activity in asymptomatic chronic active hepatitis. Hepatology 1981;1:431-435. 
Maruoka et al.

15. Wyllie AH. Glucocorticoid-induced thymocyte apoptosis is associated with endogenous endonuclease activation. Nature 1980;284:555-556.

16. Compton MM, Cidlowski JA. Rapid in vivo effects of glucocorticoids on the integrity of rat lymphocyte genomic deoxyribonucleic acid. Endocrinology 1986;118:38-45.

17. Chen X, Murakami T, Oppenheim JJ, et al. Differential response of murine CD4+CD25+ and CD4+CD25- T cells to dexamethasone-induced cell death. Eur J Immunol 2004;34:859-869.

18. Czaja AJ, Carpenter HA, Santrach PJ, et al. Significance of HLA DR4 in type 1 autoimmune hepatitis. Gastroenterology 1993;105:1502-1507.

19. Czaja AJ, Strettell MD, Thomson LJ, et al. Associations between alleles of the major histocompatibility complex and type 1 autoimmune hepatitis. Hepatology 1997;25:317-323.

20. Nishimura H, Minato N, Nakano $\mathrm{T}$, et al. Immunological studies on PD-1 deficient mice: implication of PD-1 as a negative regulator for B cell responses. Int Immunol 1998;10:1563-1572.

21. Schwabe RF, Brenner DA. Mechanisms of Liver Injury. I. TNF- $\alpha$-induced liver injury: role of IKK, JNK, and ROS pathways. Am J Physiol Gastrointest Liver Physiol 2006;290:G583-589.

22. Oksenberg JR, Stuart S, Begovich AB, et al. Limited heterogeneity of rearranged T-cell receptor $\mathrm{V} \alpha$ transcripts in brains of multiple sclerosis patients. Nature 1990;345:344-346.

23. Kim G, Tanuma N, Kojima T, et al. CDR3 size spectratyping and sequencing of spectratype-derived TCR of spinal cord T cells in autoimmune encephalomyelitis. J Immunol 1998;160:509-513.

24. Striebich CC, Falta MT, Wang Y, et al. Selective accumulation of related CD4+ $\mathrm{T}$ cell clones in the synovial fluid of patients with rheumatoid arthritis. $\mathrm{J}$ Immunol 1998;161:4428-4436.

25. Kato T, Kurokawa M, Masuko-Hongo K, et al. T cell clonality in synovial fluid of a patient with rheumatoid arthritis: persistent but fluctuant oligoclonal $\mathrm{T}$ cell expansions. J Immunol 1997;159:5143-5149.

26. Sekine T, Kato T, Masuko-Hongo K, et al. Type II collagen is a target antigen of clonally expanded $\mathrm{T}$ cells in the synovium of patients with rheumatoid arthritis. Ann Rheum Dis 1999;58:446-450.

27. Tanaka A, Iwabuchi S, Takatori $\mathrm{M}$, et al. Clonotypic analysis of $\mathrm{T}$ cells in patients with autoimmune and viral hepatitis. Hepatology 1997;25:1070-1076. 
Maruoka et al.

28. Löhr HF, Pingel S, Weyer S, et al. Individual and common antigen-recognition sites of liver-derived $\mathrm{T}$ cells in patients with autoimmune hepatitis. Scand $\mathrm{J}$ Immunol 2003;57:384-390.

29. Arenz M, Pingel S, Schirmacher $P$, et al. T cell receptor V $\beta$ chain restriction and preferred CDR3 motifs of liver-kidney microsomal antigen (LKM-1)-reactive T cells from autoimmune hepatitis patients. Liver 2001;21:18-25.

30. Dieckmann D, Plottner H, Berchtold S, et al. Ex vivo isolation and characterization of $\mathrm{CD} 4(+) \mathrm{CD} 25(+) \mathrm{T}$ cells with regulatory properties from human blood. J Exp Med 2001;193:1303-1310.

31. Baecher-Allan C, Brown JA, Freeman GJ, et al. CD4+CD25high regulatory cells in human peripheral blood. J Immunol 2001;167:1245-1253.

32. Liu W, Putnam AL, Xu-Yu Z, et al. CD127 expression inversely correlates with FoxP3 and suppressive function of human CD4+ $\mathrm{T}$ reg cells. J Exp Med 2006;203:1701-1711. 
Maruoka et al.

\section{Figure legends}

\section{Figure 1}

Either preventive or therapeutic injection of dexamethasone (DEX) suppresses fatal AlH in BALB/C-NTX-PD-1 ${ }^{-/-}$mice. In prevention, mice at one day after thymectomy were intraperitoneally injected every other day with $1.0 \mathrm{mg} / \mathrm{kg}$ of DEX diluted in PBS $(n=5)$ or PBS alone $(n=17)$. After 13 injections, mice at four weeks of age were sacrificed $(A, B, E, F)$. In therapeutic injections, mice at 14 days after thymectomy were injected every other day with DEX $(n=11)$ or PBS alone $(n=13)$. After 6 injections, mice at four weeks of age were sacrificed $(C-F)$. Survival rate $(A, C)$. Liver stainings for hematoxylin and eosin $(B, D)$. Serum levels of IgM, IgG and ANA measured by ELISA $(E)$. Serum titers of ANAs. Open circles indicate the maximum dilution of sera from individual mice as detected by fluorescence immunohistology $(F)$. Bars indicate the mean of each group, and the error bars indicate SD. Asterisks indicate $\mathrm{P}<0.05$. All scale bars, $100 \mu \mathrm{m}$.

\section{Figure 2}

Therapeutic administration of DEX reduces spleen weight but does not completely regress $T_{F H}$ cells in the spleen of BALB/C-NTX-PD-1 $1^{-1-}$ mice. Mice were injected with DEX or PBS alone preventively or therapeutically, as described in Fig. 1. (A) Spleen weights. (B) Histological analysis of the spleens from each group. Stainings for hematoxylin and eosin. Arrowheads indicate follicles. Spleens from each group were immunohistologically stained for CD4, PNA (green), and B220 (red). (C) Flow cytometric analysis of splenic CD4 ${ }^{+} \mathrm{T}^{-}$ cells from each group. Numbers in plots indicate percentage of ICOS ${ }^{+} \mathrm{CXCR}^{+}$ and $\mathrm{ICOS}^{+} \mathrm{CXCR} 5^{-}$cells in the $\mathrm{CD} 4^{+} \mathrm{T}$-cell population (left panels). Numbers of $\mathrm{ICOS}^{+} \mathrm{CXCR} 5^{+} \mathrm{CD} 4^{+} \mathrm{T}\left(\mathrm{T}_{\mathrm{FH}}\right)$ cells were calculated by (percentage of the cells in viable cells) $\times$ (No. of viable cells) (right panel). (D) Flow cytometric analysis of $\mathrm{CD}^{+}$and $\mathrm{CD}^{+} \mathrm{T}$ cells. Spleen cells of mice injected with DEX therapeutically were cultured for three days with anti-CD3, anti-CD28 mAbs, and the indicated concentration of DEX. Percentages of $7-\mathrm{AAD}^{-}$cells in $\mathrm{CD} 3^{+} \mathrm{CD} 4^{+}$and $\mathrm{CD} 3^{+} \mathrm{CD} 8^{+}$ $\mathrm{T}$ cells are shown. Data represent one of three separate experiments. $(E, F)$ Stainings for hematoxylin and eosin of the livers from recipient BALB/C-RAG2-/- 
Maruoka et al.

mice at three weeks after transfer. Total splenocytes were isolated and intravenously transferred from BALB/C-NTX-PD-1 $1^{-1-}$ mice with or without therapeutic injections of DEX $(E)$. Purified splenic $\mathrm{CD}^{+} \mathrm{T}$ cells or $\mathrm{CD} 4^{+} \mathrm{T}$-cell depleted splenocytes (CD4 cells) were transferred from BALB/C-NTX-PD-1 ${ }^{-/-}$ mice therapeutically treated with DEX $(F)$. Bars indicate the mean of each group, and the error bars indicate SD. Asterisks indicate $\mathrm{P}<0.05$. n. s., not significant. Scale bars, $100 \mu \mathrm{m}$.

\section{Figure 3}

Splenectomy overcomes therapeutic insufficiency of corticosteroids and induces prolonged remission of $\mathrm{AlH}$ in BALB/C-NTX-PD-1/- mice. $(A, B)$ Mice were injected with DEX therapeutically, as described in Fig. 1. Mice with DEX injection extended until 40 days of age (Extension, $n=7$ ) or mice with cessation of DEX injections at 4 weeks of age (Cessation, $n=10$ ) were sacrificed at 40 days. Survival rate of each group $(A)$. Stainings of the liver and spleen for hematoxylin and eosin (B). ( $C$ and $D)$ Splenectomy (Splx) was performed on BALB/C-NTX-PD-1 ${ }^{-1-}$ mice at $7(n=6)$ or 10 days $(n=5)$ before the induction and 17 $(n=6)$ or 21 days of age $(n=6)$ after the development of $A I H$. Survival rate of each group $(C)$ and liver stainings for hematoxylin and eosin at 28 days of age $(D)$. $(E)$ Survival rate at 45 days of age in BALB/C-NTX-PD-1 $1^{-/-}$mice undergoing splenectomy (Splx, $n=8$ ) or sham operation (Sham, $n=8)$ at 17 days of age. $(F)$ Mice were injected with DEX therapeutically, as described in Fig. 1. After 3 injections, mice stopped receiving DEX injections and underwent splenectomy (Splx, $n=6)$ or sham operation $(n=5)$ at 21 days of age. Survival rate of each group (left pane/). Splx mice were sacrificed at 40 days of age, and the livers were harvested. Liver stainings for hematoxylin and eosin are shown in the middle panel. For the experiment in Fig. 3F right panel, indicated mice were sacrificed at 60 days $(n=3)$. Asterisks indicate $P<0.05$. All scale bars, $100 \mu \mathrm{m}$.

\section{Figure 4}

Adult C57BL/6-NTX-PD-1 $1^{-/-}$mice spontaneously develop $B 220^{+} \mathrm{PNA}^{+}$germinal centers (GCS) with $\mathrm{CD} 4^{+} \mathrm{T}_{\mathrm{FH}}$ cells in the spleen and suffer chronic hepatitis with fibrosis. (A) Immunohistological staining of spleens in indicated mice at two to twelve weeks. The spleens were stained for CD4, CD8, PNA (green) and B220 
Maruoka et al.

(red). (B) Flow cytometric analysis of splenic B cells in indicated mice. Numbers in plots indicate percent of $B 220^{+} \mathrm{Fas}^{+} \mathrm{GL} 7^{+} \mathrm{GC}$ B cells. (C) Liver stainings for hematoxylin and eosin for C57BL/6-NTx-PD-1 $1^{-1-}$ mice at two to twelve weeks. $(D)$ Liver stainings for hematoxylin and eosin for 8-week-old ( $i$ - $v$ of left panels) and 48-week-old mice (HE, right panels). Masson's trichrome stainings of livers in 8-week-old ( $v i$ of left panels) and 48-week-old mice (MT, right panels). (E) Serum levels of AST and ALT in C57BL/6-PD-1 ${ }^{-/-}$mice at indicated ages with (closed circles) or without NTx (open circles). Bars indicate the mean of each group, and the error bars indicate SD. Asterisks indicate $\mathrm{P}<0.05$. n.s., not significant. All scale bars, $100 \mu \mathrm{m}$.

\section{Figure 5}

Adult C57BL/6-NTx-PD-1 $1^{-1-}$ mice develop hyper-gammaglobulinemia, ANA production as well as autoimmunity in other organs, and $\mathrm{T}$ cells are predominantly infiltrated in the inflamed liver. $(A$ and $B)$ The serum levels of total immunoglobulin ( $\mathrm{Ig})$ subclasses $(A)$ and ANA subclasses $(B)$ determined by ELISA. Data shown are from C57BL/6-PD-1/- mice at indicated ages with (closed bars) or without NTx (open bars). Bars indicate the mean of each group, and the error bars indicate SD. Asterisks indicate $P<0.05$. N.D., not detected. n.s., not significant. (C) Autoantibodies detected by fluorescence immunohistology as described in Supplementary Methods. Sera (x100 diluted) from 12-week-old C57BL/6-PD-1/- mice with or without NTx were used. Scale bars, $100 \mu \mathrm{m}$ (upper and middle panels) or $10 \mu \mathrm{m}$ (lower panel). (D) Histological findings of various organs from 12-week-old C57BL/6-NTX-PD-1 $1^{-1-}$ mice. Scale bars, $100 \mu \mathrm{m}$. (E) Cell numbers of each subset of liver mononuclear cells as described in Supplementary Methods. Data represent the numbers in the indicated mice at 6 weeks of age. $(F)$ Flow cytometric analysis (left panel) and cell numbers (right panel) of $\mathrm{CD}^{+} \mathrm{CD} 4^{+}$and $\mathrm{CD}^{+} \mathrm{CD} 8^{+} \mathrm{T}$ cells in the liver of 6-week-old C57BL/6-PD-1/- mice with or without NTx. Numbers in quadrants indicate percentage of cells in that gate (left panel). Data shown in Fig. 5C, E and $F$ are from one of three separate experiments.

Figure 6 
Maruoka et al.

Splenic $\mathrm{CD}^{+} \mathrm{T}$ cells are responsible for induction of chronic $\mathrm{AlH}$, and $\mathrm{CD} 4^{+} \mathrm{T}$ cells infiltrated in the liver show clonal expansion in NTx-PD-1 $1^{-1-}$ mice. $(A)$ Immunohistological staining of livers. The livers in 6-week-old C57BL/6-PD-1 ${ }^{-1-}$ mice with or without NTx were stained with FITC-anti-CD4 or -anti-CD8. The insets show stainings for CD4 or CD8 with a higher magnification. Scale bars, $100 \mu \mathrm{m}$. (B) Macroscopic view of the liver, spleen, and mesenteric lymph node (MLN) from 12-week-old indicated mice. Scale bars, $1 \mathrm{~cm}$. (C) Purified $\mathrm{CD}^{+} \mathrm{CD}^{+} \mathrm{T}$ cells from the spleen of 8-week-old C57BL/6-PD-1 ${ }^{-1-}$ mice with or without NTx were transferred into RAG2 ${ }^{-/-}$mice intravenously. Three weeks after transfer, recipient mice were examined. Liver stainings for hematoxylin and eosin. Scale bars, $100 \mu \mathrm{m}$ (left panel). Serum levels of the liver transaminases, AST and ALT (right panel). (D) Serum levels of TNF- $\alpha$ and IFN- $\gamma$ in 6-week-old indicated mice as measured by ELISA. (E) Serum levels of TNF- $\alpha$ in recipient mice transferred as described in Fig. $6 C$. $(F) \mathrm{TCR}_{\beta}$ usages of hepatic $\mathrm{CD}^{+} \mathrm{T}$ cells in indicated mice assessed by flow cytometry. Mononuclear cells in the liver were stained as described in Supplementary Methods. Data shown are from one of three separate experiments. Bars in Fig. 6C-E indicate the mean of each group, and the error bars indicate SD. Asterisks indicate $\mathrm{P}<0.05$. n.s., not significant. N.D., not detected.

\section{Figure 7}

C57BL/6-NTX-PD-1/- mice at 4 weeks of age show increased serum levels of the liver transaminases, and therapeutic injections of DEX as well as splenectomy suppress chronic AIH. (A) Serum levels of the liver transaminases AST and ALT in four-week-old indicated mice. $(B)$ Intraperitoneal injections of DEX $(n=5)$ or PBS $(n=5)$ were started at four weeks. After 14 injections every other day until eight weeks of age, mice were sacrificed and examined. (C) Mice underwent a splenectomy (NSplx, $n=5$ ) or a sham operation $(n=5)$ at one day after NTx, and were analyzed at eight weeks. (D) Four-week-old mice underwent a splenectomy (Splx, $n=5)$ or a sham operation $(n=5)$ and were analyzed at eight weeks. ( $E$ and $F$ ) Twelve-week-old mice underwent a splenectomy (Splx, n=5) or a sham operation $(n=5)$ and were analyzed at 20 weeks. Liver stainings for hematoxylin and eosin (B-E) and serum levels of AST and ALT ( $A$ and $F$ ). Bars indicate the mean of each group, and the error bars indicate SD. Asterisks indicate $\mathrm{P}<0.05$. Scale bars, $100 \mu \mathrm{m}$. 
Maruoka et al.

Fig. 1

A

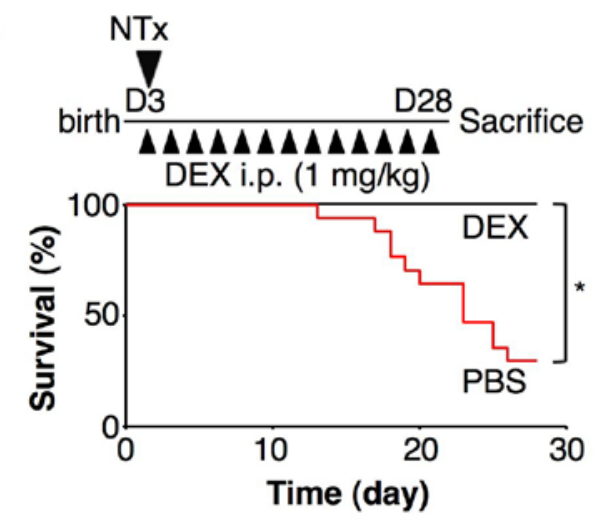

C

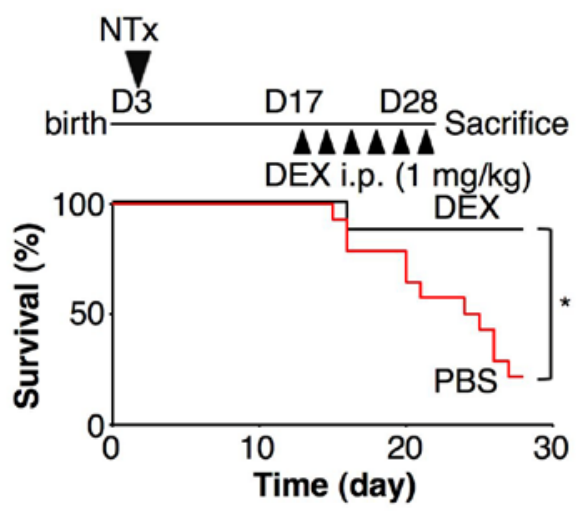

E

$\underline{\text { Treatment }}$
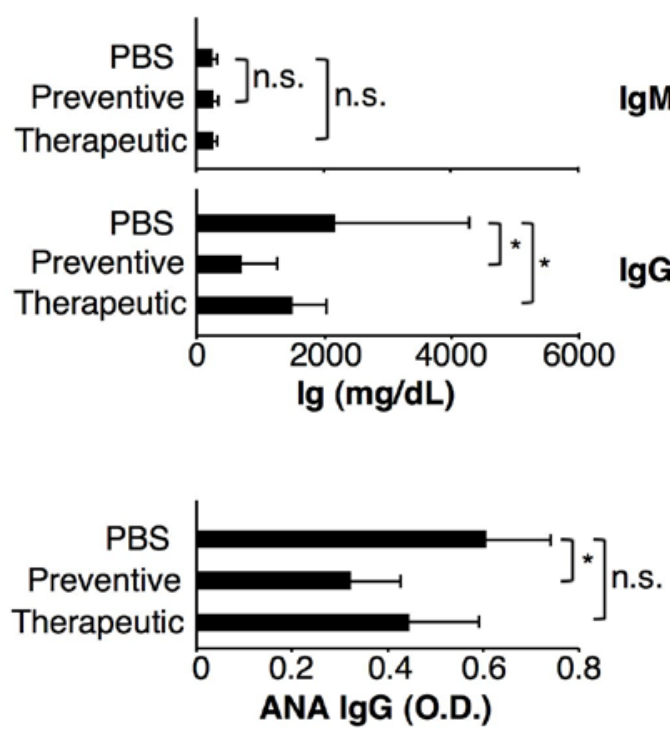

B

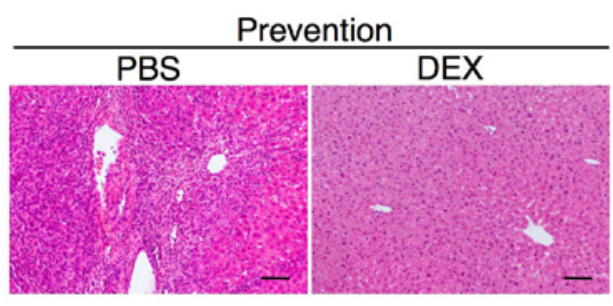

D

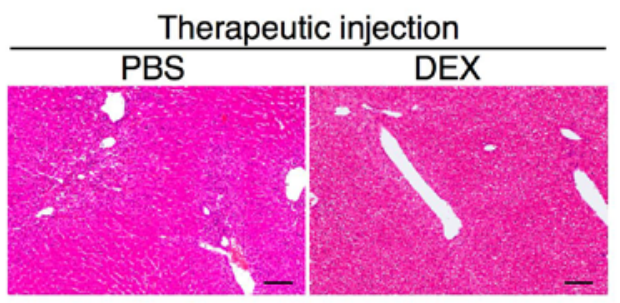

$\mathbf{F}$

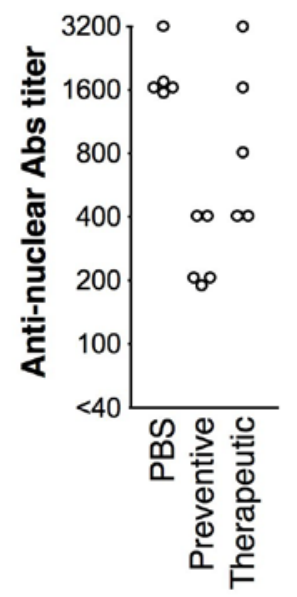


Maruoka et al.

Fig. 2

A

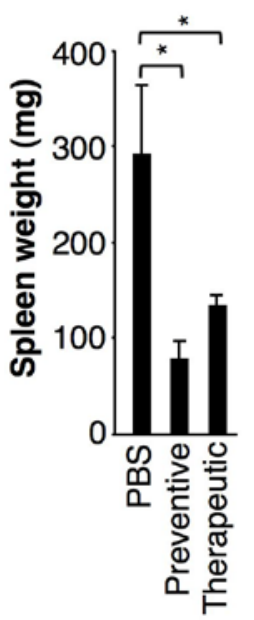

B

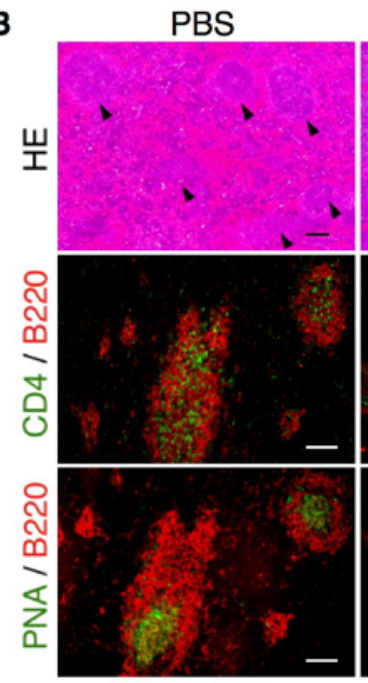

Preventive

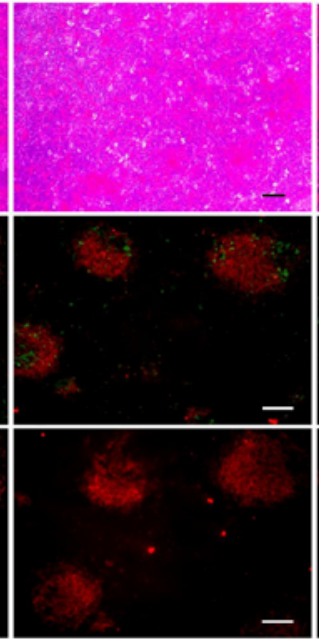

Therapeutic

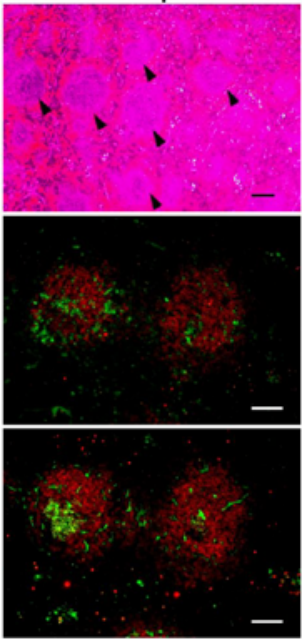

C
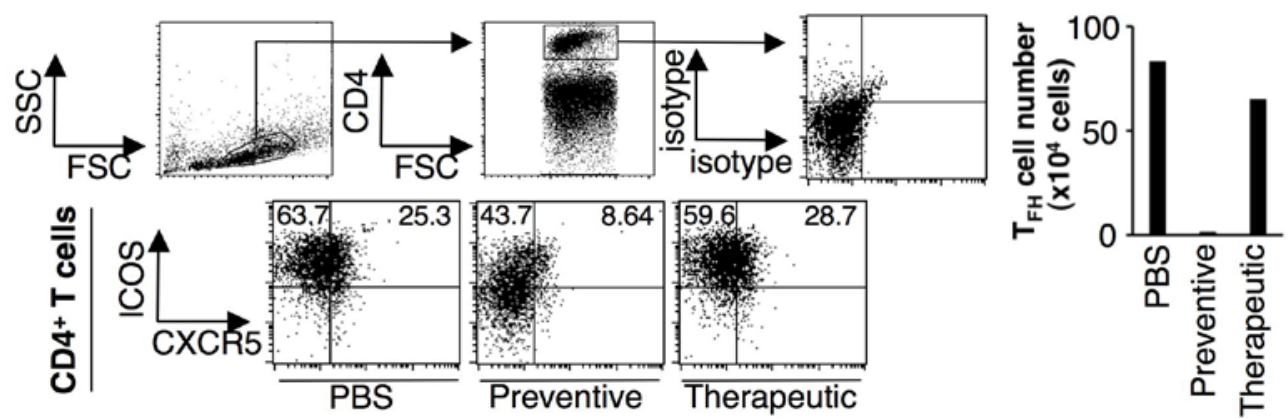

D
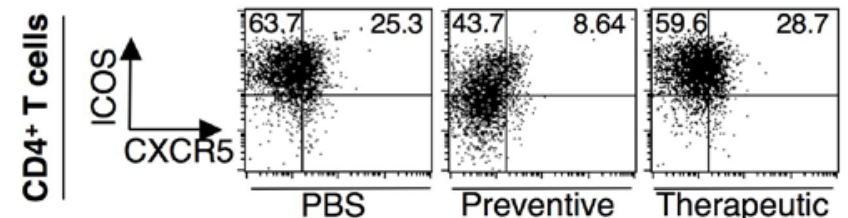

E

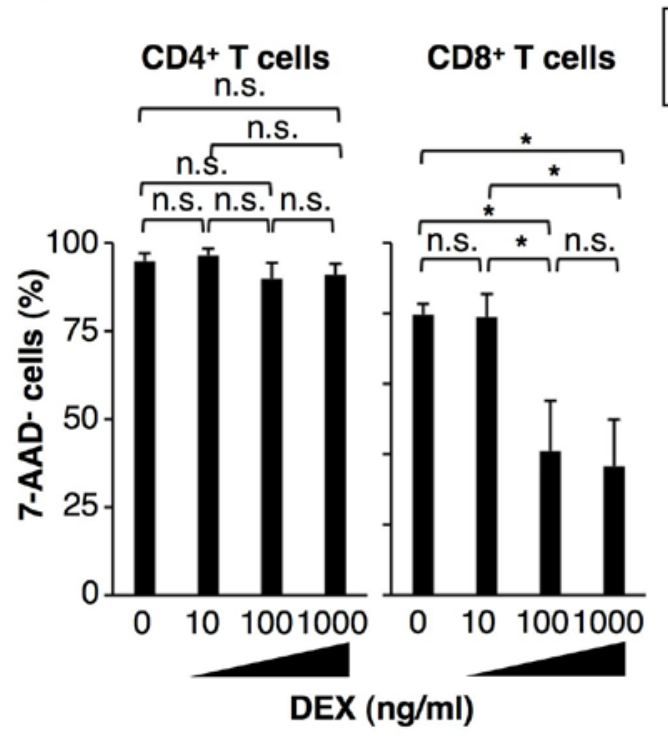

Donor

Spleen
BALB/c
RAG2KO

$\mathbf{F}$

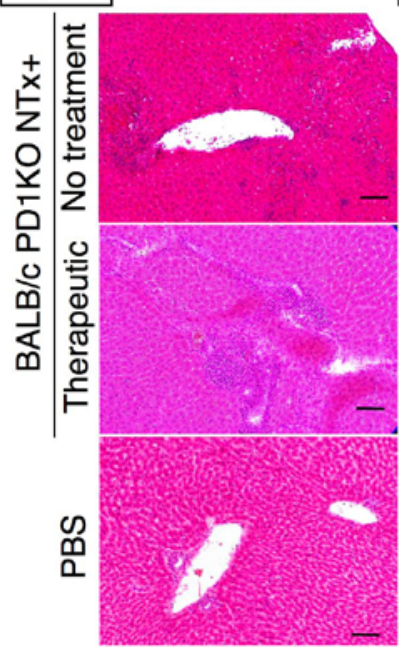

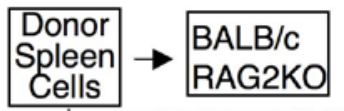

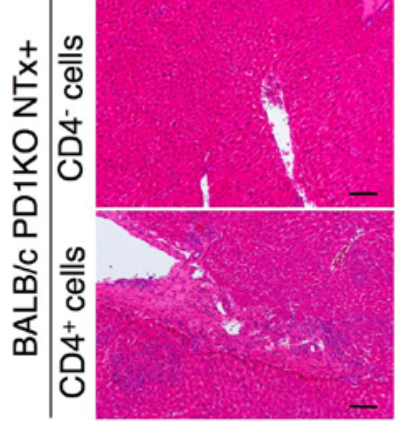


Maruoka et al.

Fig. 3

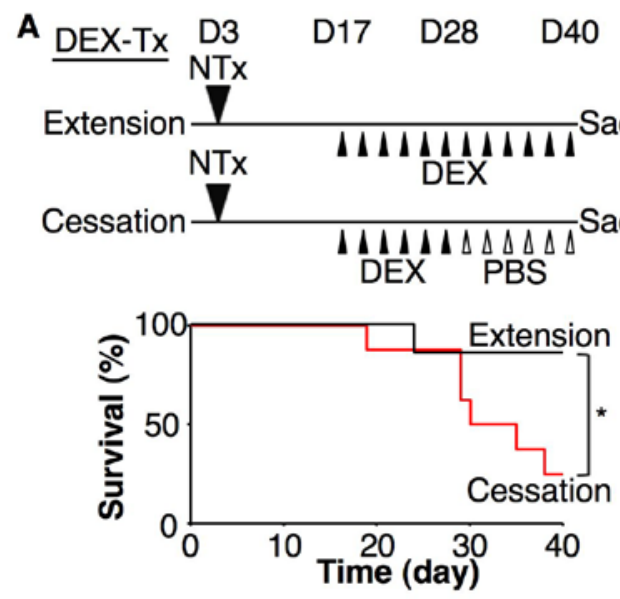

C

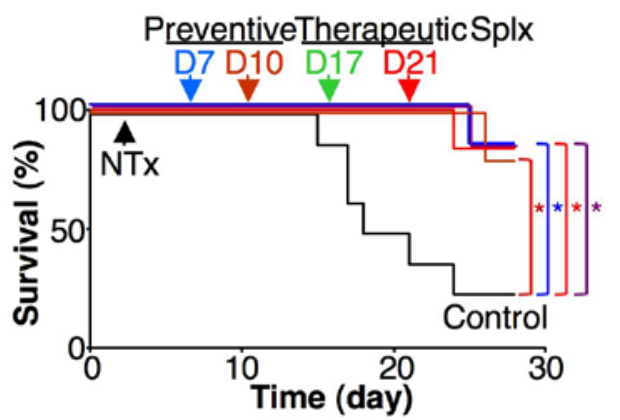

D

B Liver Spleen
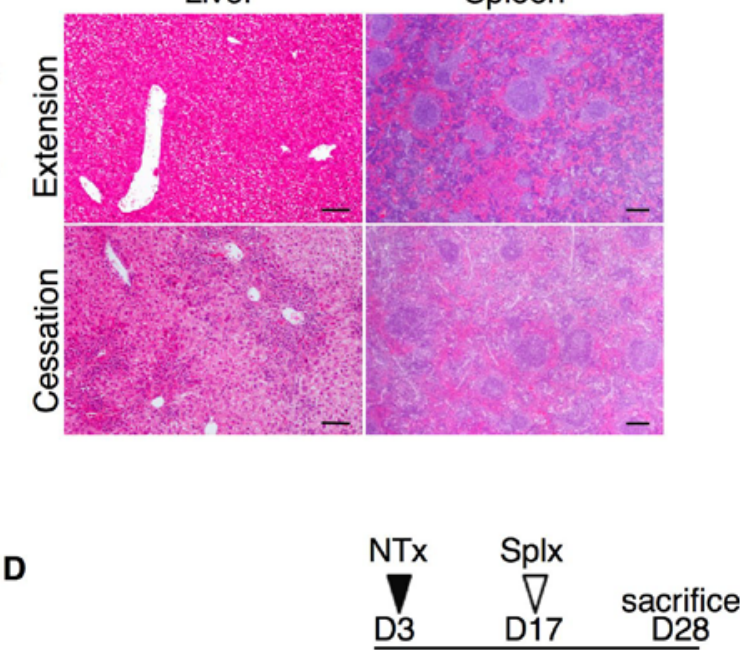

E
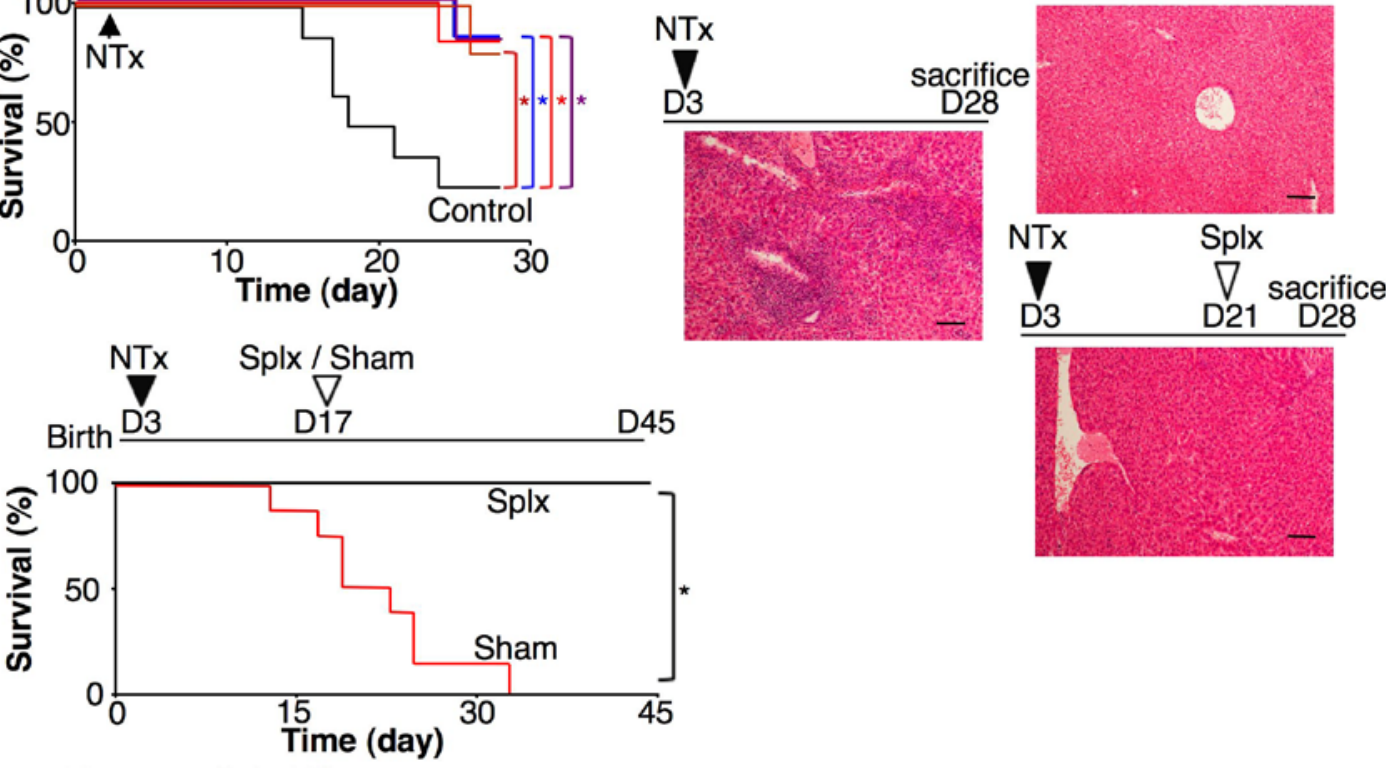

F NTx Splx/Sham
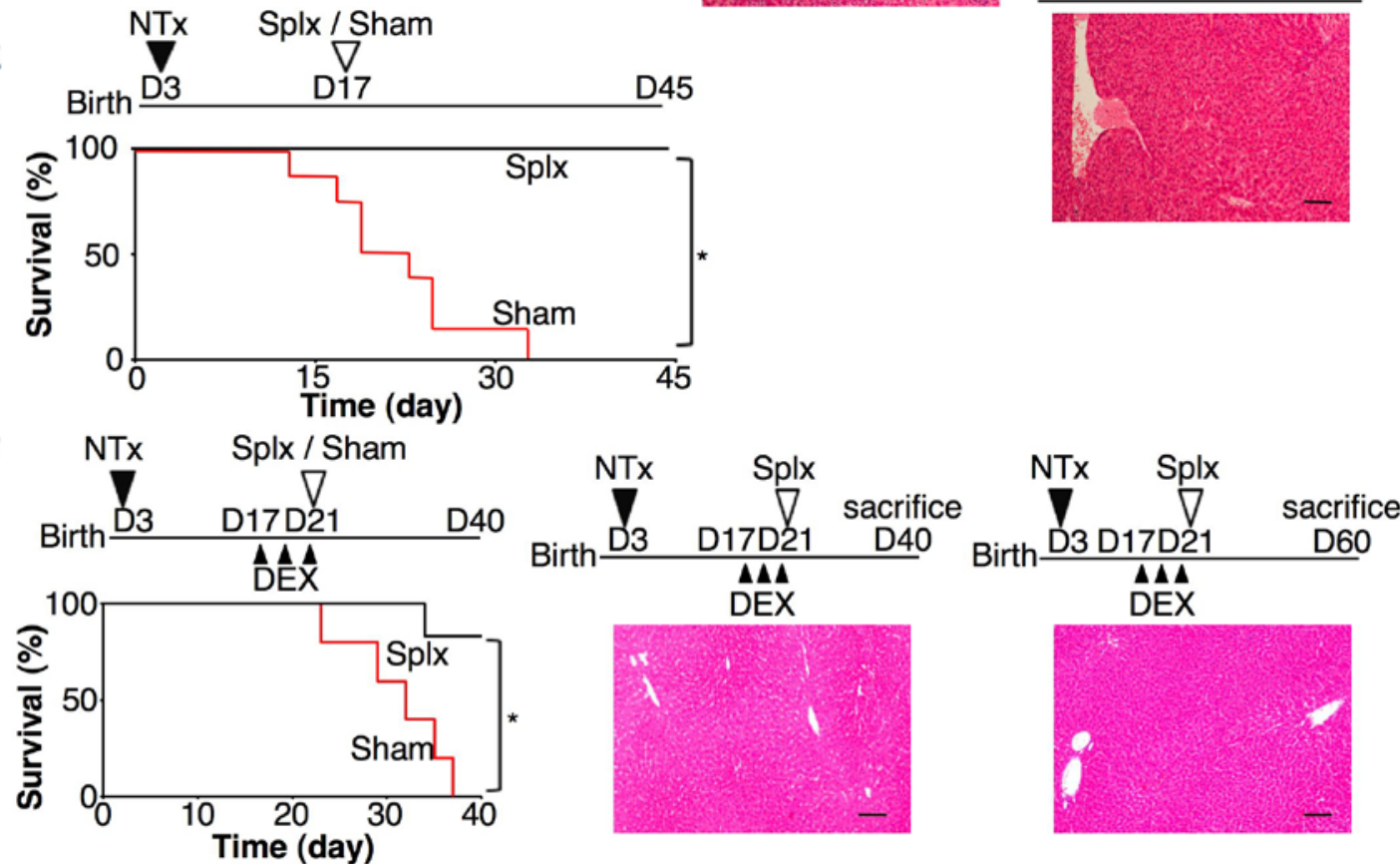
Maruoka et al.

Fig. 4

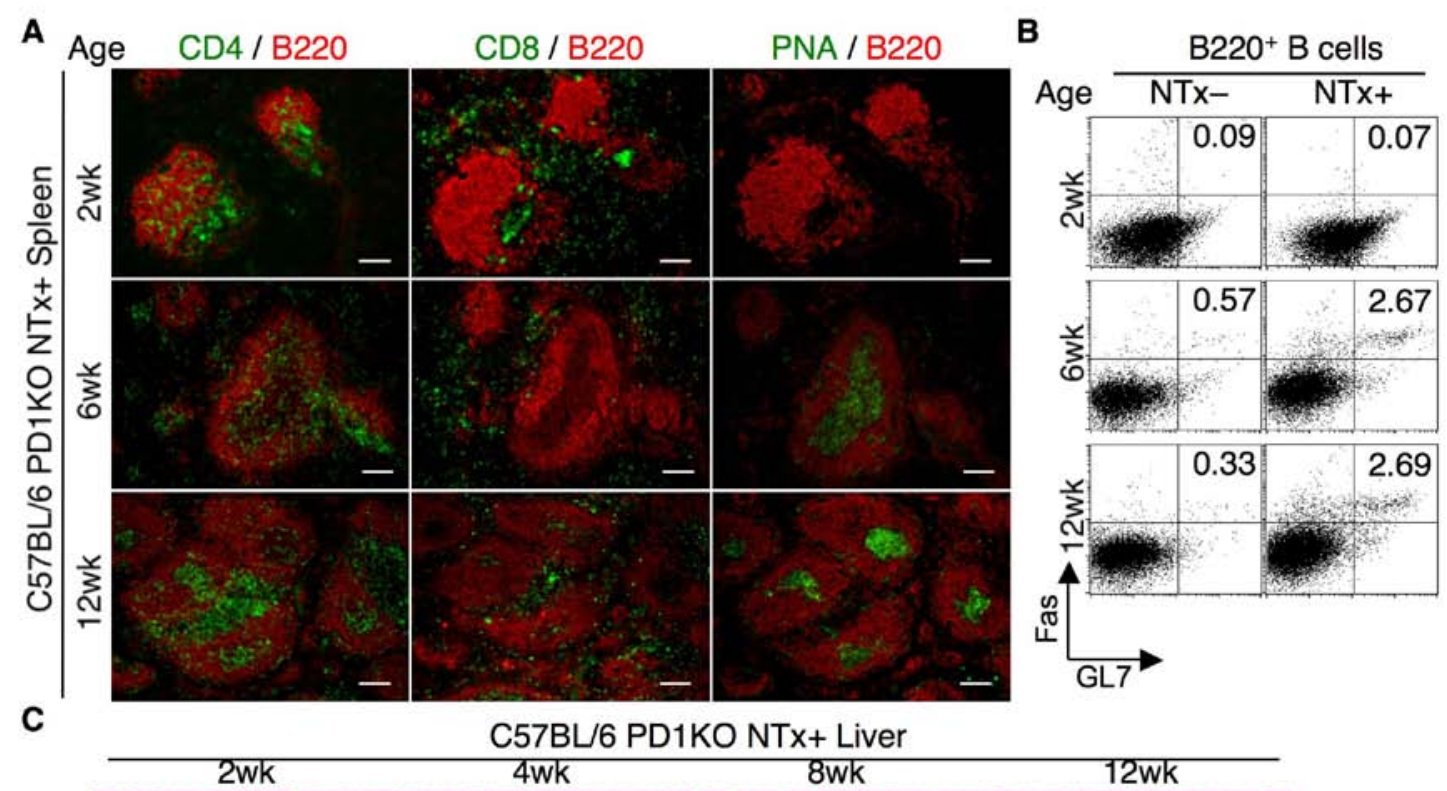

D

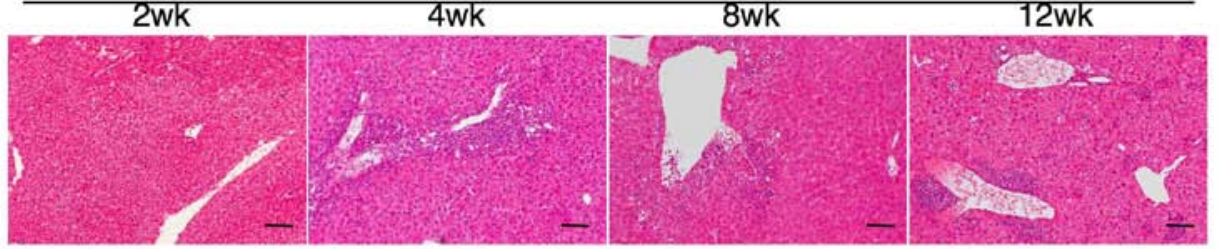

8wk Liver
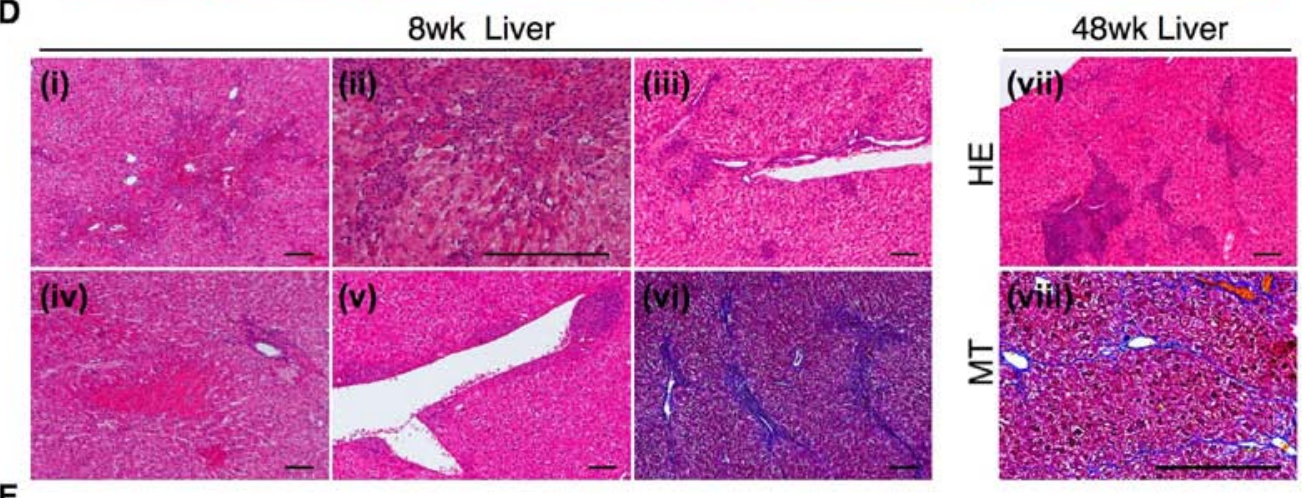

E

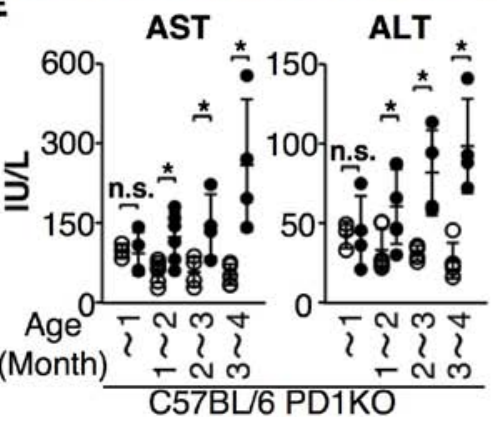


Maruoka et al.

Fig. 5
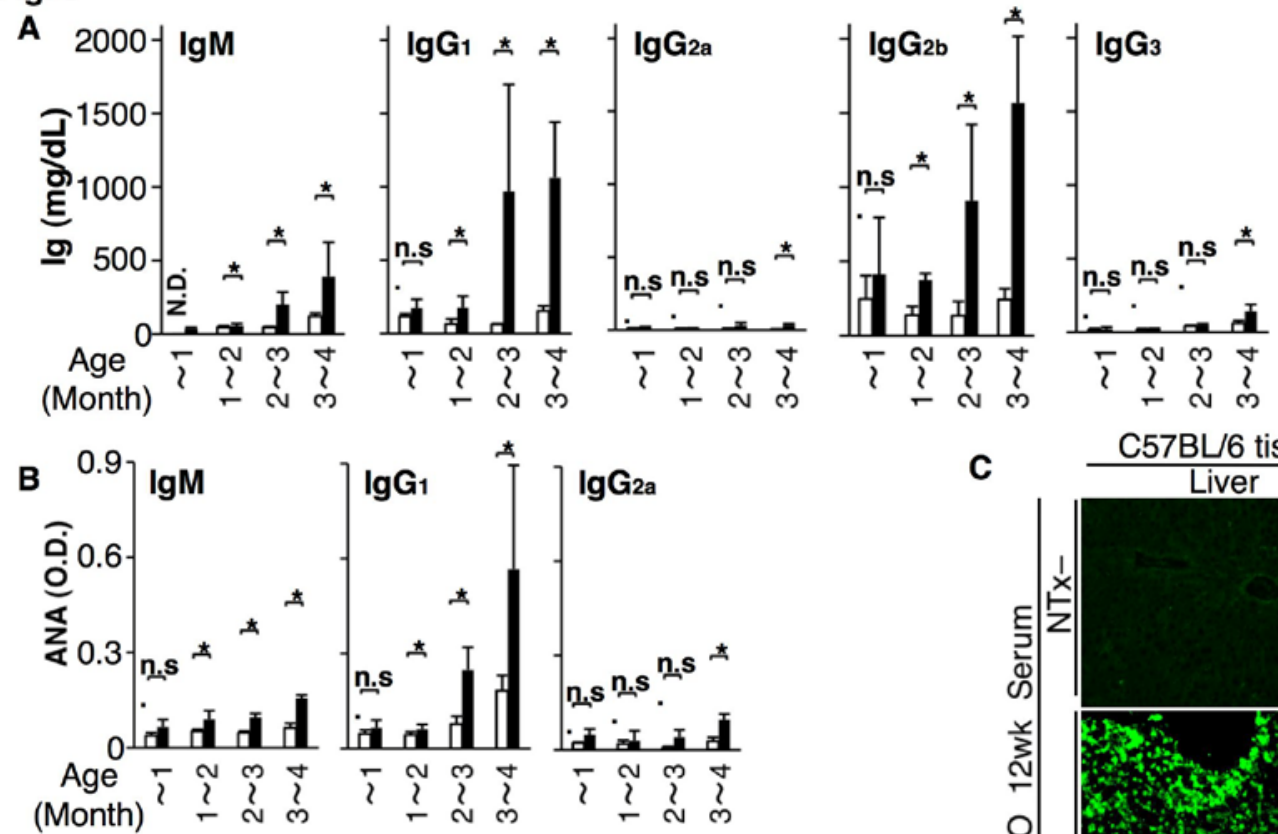

D

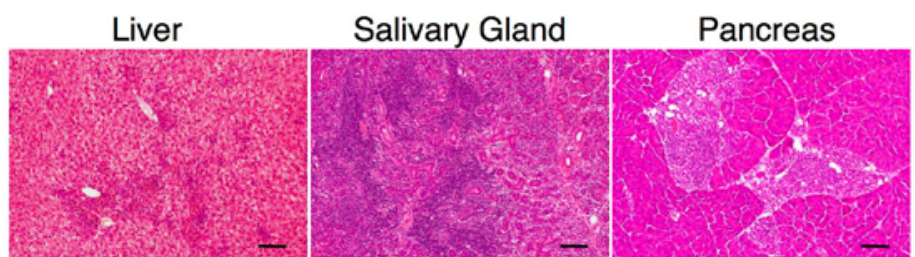

c C57BL6 tissue

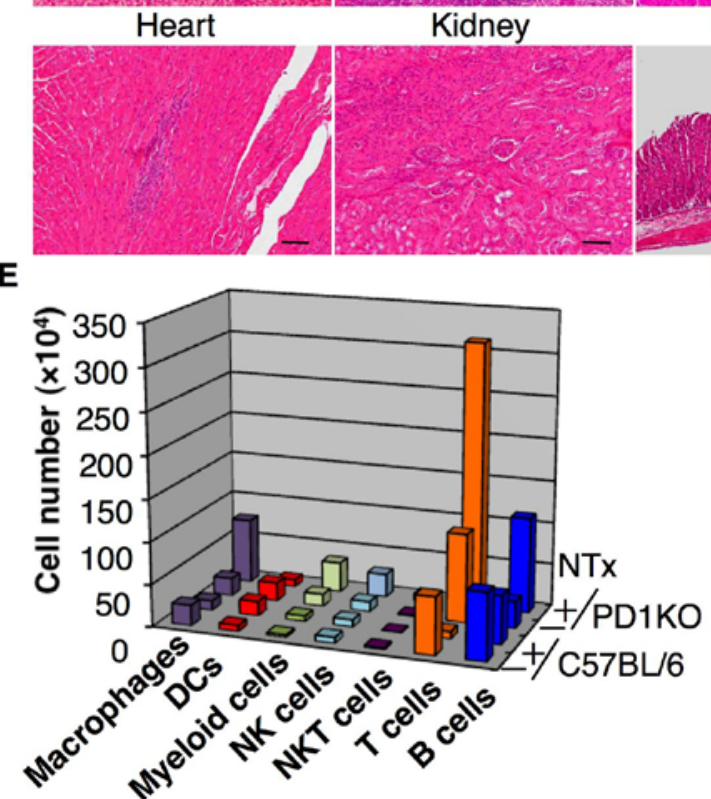

F

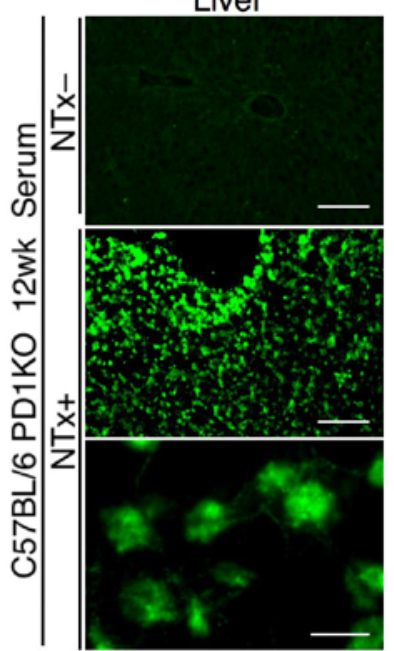

Lung

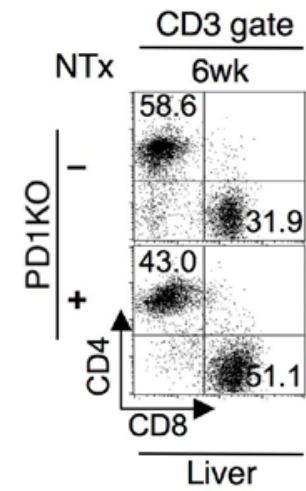

口 CD4 $\square \mathrm{CD} 8$

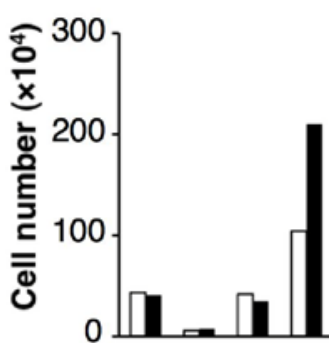

NTx -+-+

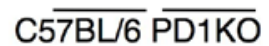


Maruoka et al.

Fig. 6

A

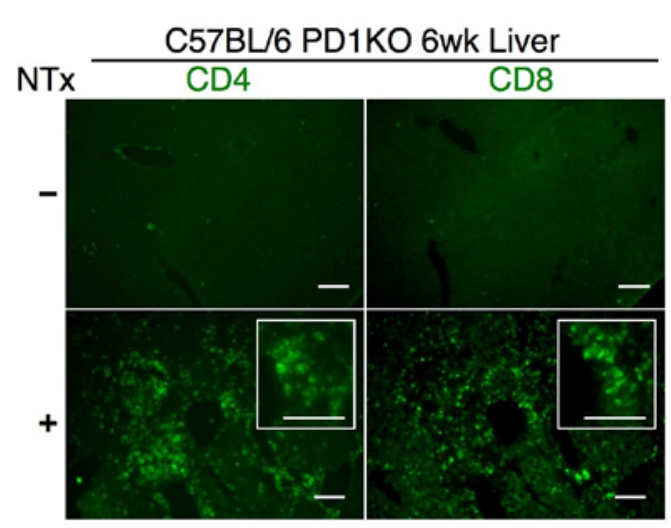

C

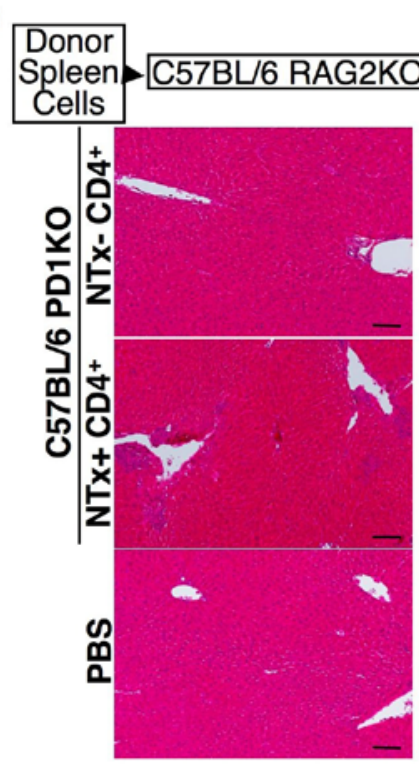

E

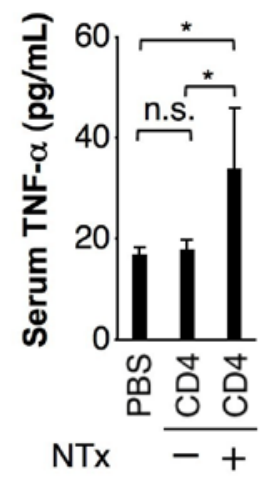

$\mathbf{F}$

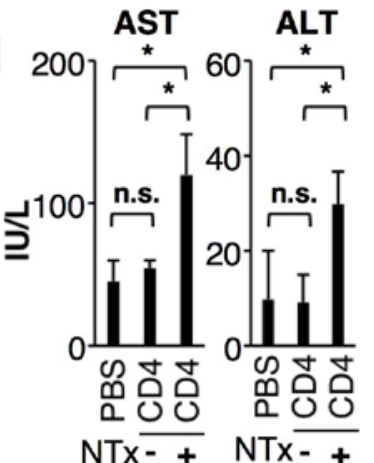

D

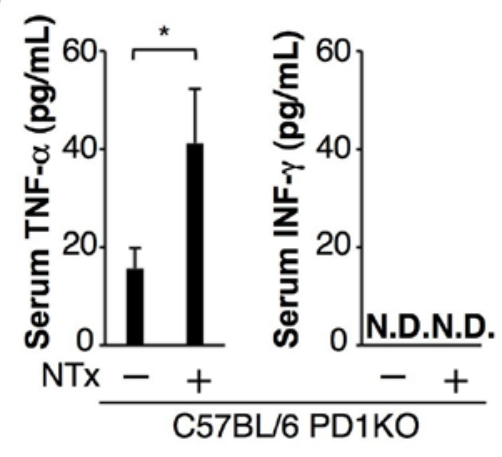

B
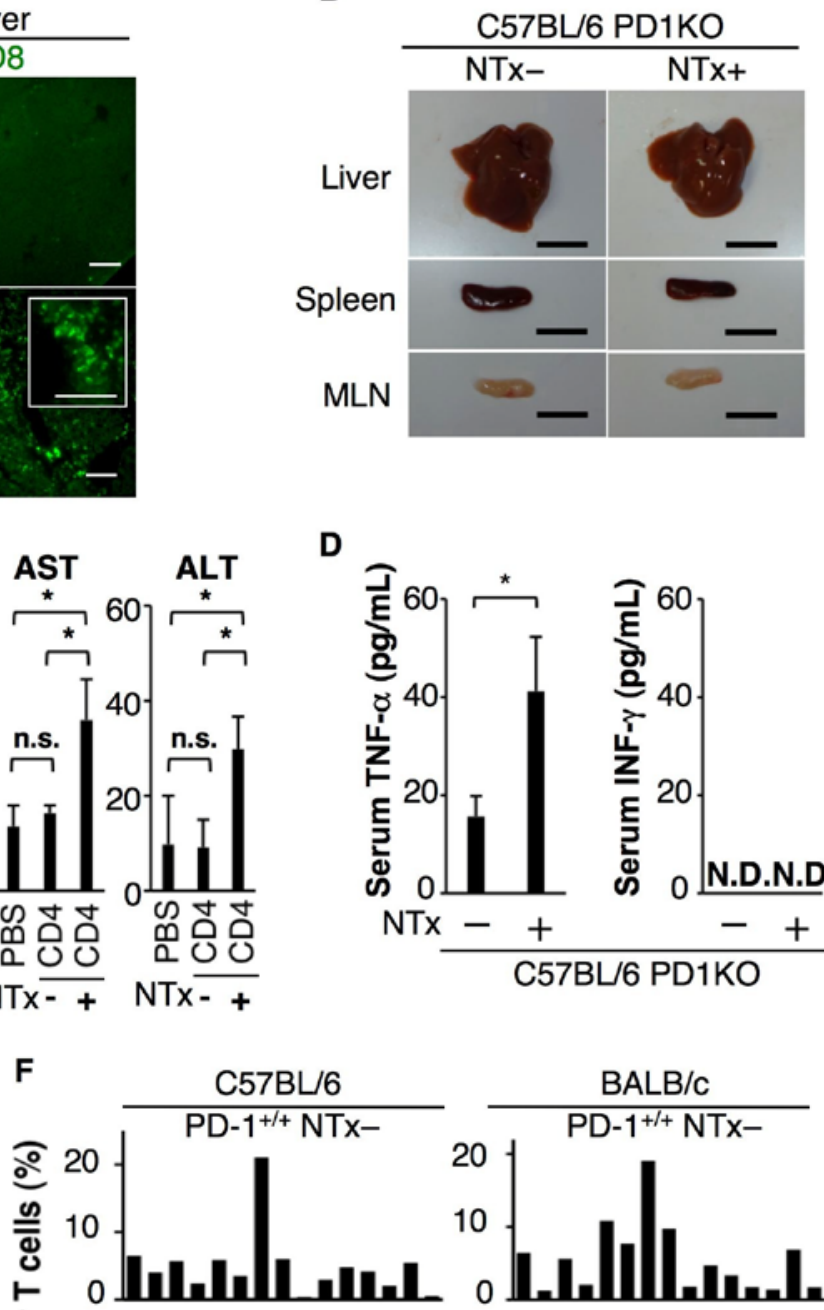

+ 20 PD-1KO NTX- PD-1KO NTX-

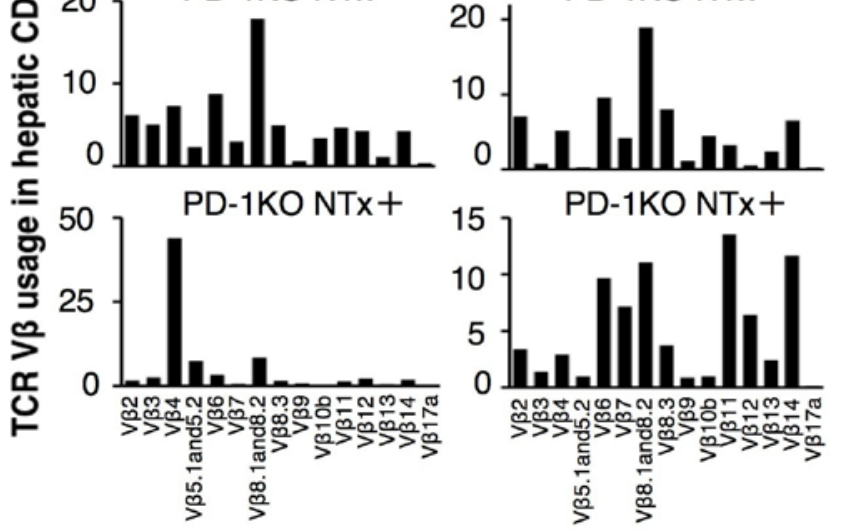


Maruoka et al.

Fig. 7

A

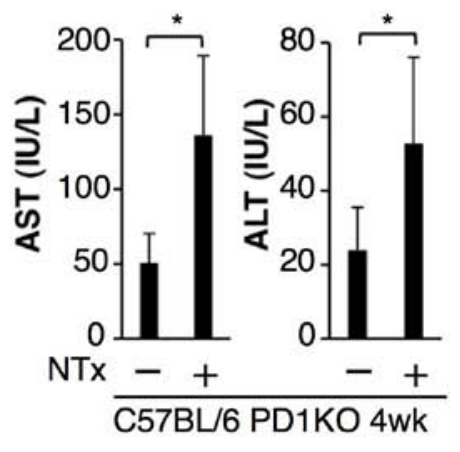

C
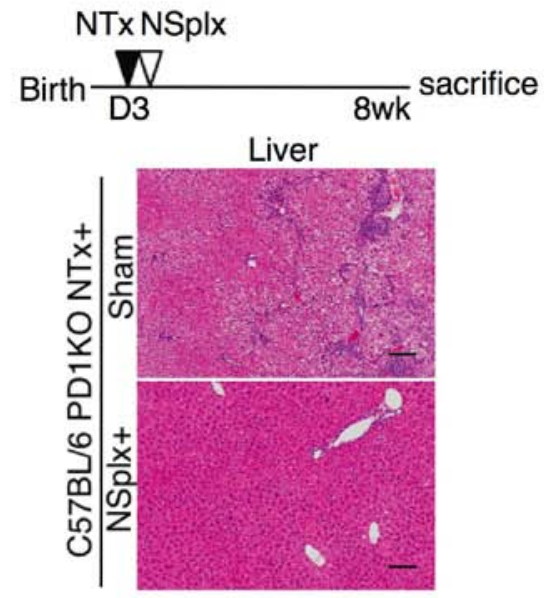

E
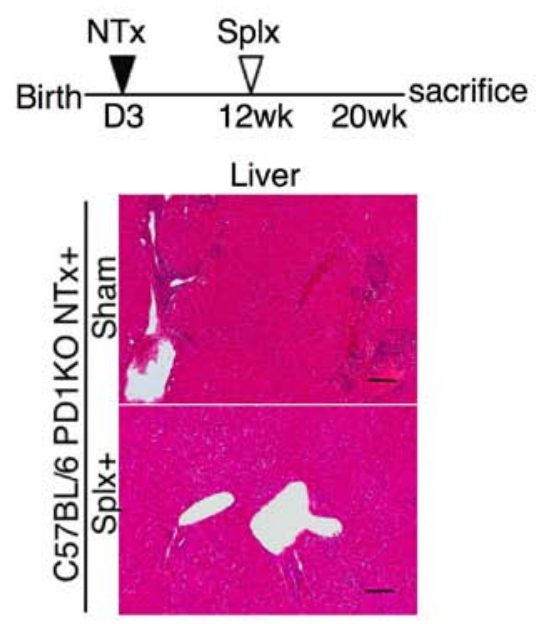

B

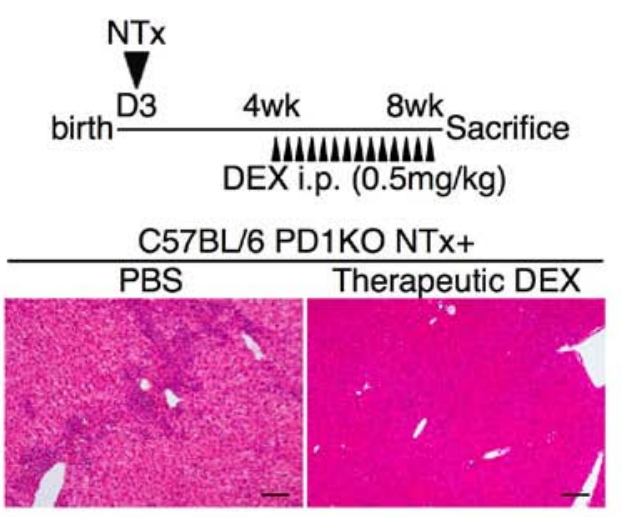

D
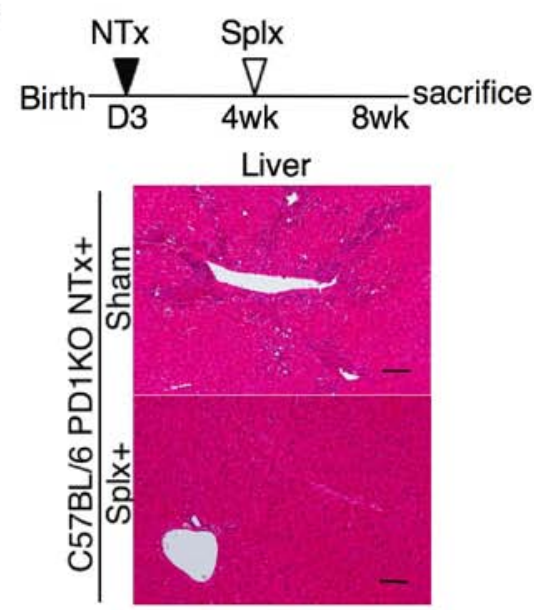

$\mathbf{F}$

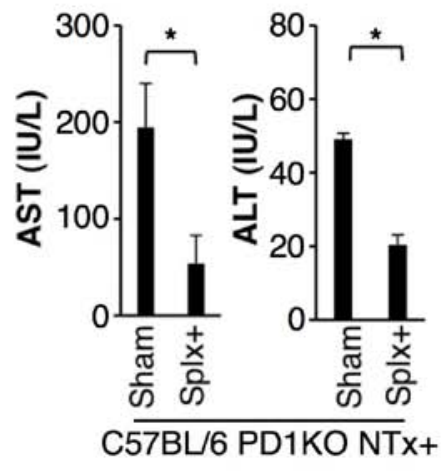




\section{<Supplementary information>}

\section{Supplementary Methods}

Mice

C57BL/6 and BALB/C mice were purchased from Japan SLC (Shizuoka, Japan), and $P D-1^{-/-}$and $R A G-2^{-/-}$mice on a C57BL/6 or BALB/c background were generated as described. ${ }^{1-3}$ All of these mice were bred and housed under specific pathogen-free conditions. Thymectomy and splenectomy of the mice were performed as described. ${ }^{4-6}$ The sham splenectomy was performed by cutting the peritoneum without removing the spleen. All mouse protocols were approved by the Institute of Laboratory Animals, Graduate School of Medicine, Kyoto University.

\section{Administration of dexamethasone (DEX) in vivo}

For the preventive protocol, BALB/c-NTx $-P D-1^{-/-}$mice at one day after thymectomy were intraperitoneally injected every other day with $1.0 \mathrm{mg} / \mathrm{kg}$ of DEX (Sigma-Aldrich, St. Louis, MO) diluted in phosphate-buffered saline (PBS) or PBS alone. After 13 injections, mice at four weeks of age were sacrificed, and the livers, spleens, and sera were harvested. For the therapeutic protocol, BALB/c-NTx $-P D-1^{-/-}$ mice at 14 days after thymectomy were intraperitoneally injected every other day with $1.0 \mathrm{mg} / \mathrm{kg}$ of DEX diluted in PBS or PBS alone. In C57BL/6-NTx-PD-1 ${ }^{-/-}$mice, the therapeutic injections of $0.5 \mathrm{mg} / \mathrm{kg}$ of DEX every other day were started at 4 weeks of age. After indicated injections, mice were sacrificed.

\section{Histological and immunohistological analysis}

Organs were fixed in neutral buffered formalin and embedded in paraffin wax. Sections were stained with hematoxylin and eosin or Masson's trichrome for histopathology. Fluorescence immunohistology was performed on frozen sections as described previously ${ }^{4,5}$ using FITC-conjugated anti-CD4 (RM4-5), anti-CD8a (Ly-2) (eBioscience, San Diego, CA), peanut agglutinin (PNA, Vector Laboratories, Burlingame, CA), biotin-labeled anti-B220 (RA3-6B2) (BD Biosciences, San Jose, CA) followed by Texas red-conjugated avidin (Vector Laboratories). To detect autoantibodies, livers were collected from wild-type BALB/c and C57BL/6 mice. 
Maruoka et al.

Sections were stained with x100 to x3200 diluted sera from indicated mice, followed by FITC-conjugated anti-mouse IgG (Cappel, Chester, PA). ${ }^{4}$

\section{Flow cytometry analysis and isolation of lymphocytes}

Single cells from the livers and spleens were prepared as described. ${ }^{4,5}$ The following monoclonal antibodies (mAbs) were used for surface staining: FITC-conjugated anti-CD4, anti-CXCR5 (2G8), anti-GL7, anti-CD11c (HL3) (BD Biosciences), anti-DX5 (eBioscience); PE-conjugated anti-CD3e (145-2C11), anti-ICOS, anti-Gr-1 (RB6-8C5) (eBioscience); anti-CD95/Fas (Jo2) (BD Biosciences); APC-Cy7-conjugated anti-CD4 (GK1.5), biotin-labeled B220 (BD Biosciences); and APC-conjugated streptavidin, anti-CD8a, and anti-CD25 (PC61.5), anti-CD11b (M1/70) (eBioscience). For flow cytometric analysis of splenic CD4 ${ }^{+} \mathrm{T}$ cells in Figure 2C and Supplementary Figure 6A, spleen cells were stained with FITC-anti-CXCR5, PE-anti-ICOS, APC-Cy7-anti-CD4. To analyze splenic B220 ${ }^{+} \mathrm{B}$ cells in Figure 4B, cells were stained with FITC-anti-GL7, PE-anti-CD95/Fas, and biotin-labeled B220 followed by APC-conjugated streptavidin. Data of flow cytometric analysis in Figure $5 E$ and $5 F$ represent cell numbers of the following cell

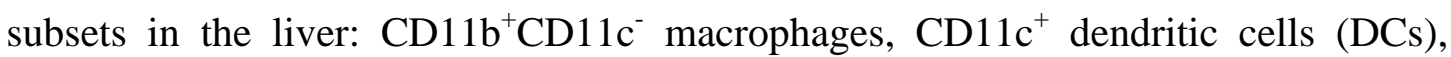

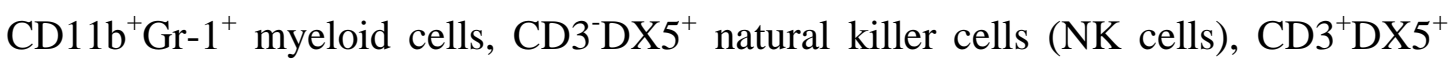
natural killer $\mathrm{T}$ cells (NKT cells), $\mathrm{CD}^{+}{ }^{-} \mathrm{DX} 5^{-} \mathrm{T}$ cells, $\mathrm{B} 220^{+} \mathrm{B}$ cells, $\mathrm{CD}^{+} \mathrm{CD}^{+} \mathrm{T}$ cells and $\mathrm{CD}^{+} \mathrm{CD}^{+} \mathrm{T}$ cells. For the analysis of $\mathrm{T}$ cell receptor (TCR) $\mathrm{V}_{\beta}$ usage in Figure $6 F$, cells were stained with FITC-anti- $\mathrm{V}_{\beta} 2$ (B20.6), anti- $\mathrm{V}_{\beta} 3(\mathrm{KJ} 25)$, anti- $\mathrm{V}_{\beta} 4$ (KT4), anti- $\mathrm{V}_{\beta} 5.1$ and $\mathrm{V}_{\beta} 5.2$ (MR9-4), anti- $\mathrm{V}_{\beta} 6$ (RR4-7), anti- $\mathrm{V}_{\beta} 7$ (TR310), anti- $\mathrm{V}_{\beta} 8.1$ and $\mathrm{V}_{\beta} 8.2$ (MR5-2), anti- $\mathrm{V}_{\beta} 8.3$ (IB3.3), anti- $\mathrm{V}_{\beta}$ 9 (MR10-2), anti- $\mathrm{V}_{\beta} 10^{\mathrm{b}}$ (B21.5), anti- $\mathrm{V}_{\beta} 11$ (RR3-5), anti- $\mathrm{V}_{\beta} 12$ (MR11-1), anti- $\mathrm{V}_{\beta} 13$ (MR12-3), anti- $\mathrm{V}_{\beta} 14$ (14-2), anti- $\mathrm{V}_{\beta} 17^{\mathrm{a}}$ (KJ23), PE-anti-CD3e, and APC-Cy7-anti-CD4 for CD4 ${ }^{+} \mathrm{T}$ cells by using Mouse $V_{\beta}$ TCR Screening Panel (BD Biosciences). Stained cells were analyzed with a FACSCanto ${ }^{\mathrm{TM}}$ II (BD Biosciences). Data were analyzed using Cell Quest Pro ${ }^{\mathrm{TM}}$ (BD Biosciences). Dead cells were excluded on the basis of side- and forward-scatter characteristics, and viable cell numbers were calculated as follows: (the percentage of cells in the cell type) $\times$ (the number of viable cells). For 7-AAD staining in Figure 2D, single cells were isolated from the spleens of 3-week-old $\mathrm{BALB} / \mathrm{c}-\mathrm{NTx}-\mathrm{PD}-1^{-/-}$mice injected with DEX therapeutically. Isolated spleen cells $\left(1 \times 10^{6}\right)$ were cultured with $10-1000 \mathrm{ng} / \mathrm{ml}$ of DEX under plate-bound anti-CD3 (1 
Maruoka et al.

$\mu \mathrm{g} / \mathrm{ml})$ and soluble anti-CD28 $(5 \mu \mathrm{g} / \mathrm{ml})$. Round-bottomed 96-well culture plates were used with D-MEM supplemented with $10 \%$ fetal bovine serum, $50 \mathrm{mmol} / \mathrm{L}$ 2-mercaptoethanol, $100 \mathrm{U} / \mathrm{ml}$ penicillin, and $100 \mu \mathrm{g} / \mathrm{ml}$ streptomycin. Three days after the culture, cells were harvested and stained with FITC-conjugated anti-CD3e (eBioscience) and 7-AAD (BD Biosciences) and either PE-Texas Red-conjugated anti-CD4 (Abcam, Cambridge, UK) or PE-Texas Red-conjugated anti-CD8 (Abcam). In Foxp3 staining, cells were fixed and permeabilized using Foxp3 staining buffer (eBioscience) and stained with PE-anti-Foxp3 (eBioscience).

\section{ELISA}

Serum immunoglobulin (Ig) levels were determined by ELISA as described, ${ }^{7}$ and $\mathrm{Ab}$ sets to detect mouse IgG1, IgG2a, IgG2b, IgG3 from BD Biosciences and anti-mouse IgM from AbD Serotec (Oxford, UK) were used. To detect serum ANAs, microtiter plates (Nunc, Roskilde, Denmark) were incubated with $10 \mu \mathrm{g} / \mathrm{ml}$ antigens, and the nuclear fraction was prepared from normal liver. ${ }^{8} \mathrm{Ab}$ sets to detect mouse ANA subclasses were the same as above. Serum concentrations of TNF- $\alpha$ and IFN- $\gamma$ were measured with mouse cytokine ELISA sets from eBioscience according to the manufacturer's protocols.

\section{Isolation of lymphocytes and adoptive transfer}

For transfer of total spleen cells, BALB/c-NTx $-P D-1^{-/-}$mice at 14 days after thymectomy were intraperitoneally injected every other day with or without 1.0 $\mathrm{mg} / \mathrm{kg}$ of DEX diluted in PBS. Single cells were isolated from the spleens of 3-week-old mice. Isolated spleen cells $\left(1 \times 10^{7}\right)$ were intravenously injected into $R A G 2^{-/-}$recipient mice on a BALB/c background at 4-6 weeks of age. To transfer $\mathrm{CD}^{+} \mathrm{T}$ cells or $\mathrm{CD} 4^{+} \mathrm{T}$ cell-depleted spleen cells, 3-week-old BALB/c-NTx-PD-1 ${ }^{-/-}$ mice were therapeutically injected with DEX. Cells were prepared using mouse CD4 microbeads (Miltenyi Biotec, Bergisch Gladbach, Germany), according to the manufacturer's protocols. Purity was assessed by flow cytometry. CD4 ${ }^{+} \mathrm{T}$ cells were purified to reach $>90 \%$ purity, and $\mathrm{CD}^{-}$splenocytes reached $>99 \%$ purity. Isolated cells $\left(1 \times 10^{6}\right)$ were intravenously injected into BALB/c-RAG2 $2^{-/}$mice at $4-6$ weeks of age. 
Maruoka et al.

For transfer of $\mathrm{CD} 4^{+} \mathrm{T}$ cells from C57BL/6-PD- $1^{-/-}$mice, $\mathrm{CD}^{+} \mathrm{CD} 4^{+} \mathrm{T}$ cells were prepared from the spleens of 8-week-old C57BL/6-PD-1/- mice with or without NTx obtained by a FACS AriaTMII. Isolated CD3 ${ }^{+} \mathrm{CD}^{+} \mathrm{T}$ cells $\left(1 \times 10^{6}\right)$ were intravenously injected into $\mathrm{C} 57 \mathrm{BL} / 6-R A G 2^{-/-}$recipient mice at 4-6 weeks of age. For transfer, $\mathrm{CD} 4^{+} \mathrm{CD} 25^{+}$regulatory $\mathrm{T}$ cells (Tregs) were purified from the spleens of eight-week-old C57BL/6-PD-1 ${ }^{-/}$mice. Tregs were obtained by a FACS Aria ${ }^{\mathrm{TM}}$ II and isolated with a $\mathrm{CD} 4{ }^{+} \mathrm{CD} 25^{+} \mathrm{T}$ cell to reach $>99 \%$ purity. Tregs $\left(1 \times 10^{6}\right)$ were intravenously injected into $\mathrm{C} 57 \mathrm{BL} / 6-\mathrm{NTx}-P D-1^{-/-}$mice at 4 weeks of age. Four weeks post-transfer, the recipient mice at 8 weeks of age were sacrificed.

\section{Histological activity index (HAI) score}

Histological activity of chronic active hepatitis was assessed according to a semiquantitative scoring system, as described previously for humans. ${ }^{9}$ For histological assessment, all specimens were reviewed blind by at least two hepatologists. Using Knodell's HAI scoring system, liver specimens were graded in four categories. Category I, periportal and/or bridging hepatocellular necrosis was graded from 0 to 10 , where $0=$ none, $1=$ mild piecemeal necrosis, $3=$ moderate piecemeal necrosis (involves less than $50 \%$ of the circumference of most portal tracts), $4=$ marked piecemeal necrosis (involves more than $50 \%$ of the circumference of most portal tracts), 5=moderate piecemeal necrosis plus bridging necrosis, $6=$ marked piecemeal necrosis plus bridging necrosis, $10=$ multilobular necrosis. Category II, intralobular degeneration and focal hepatocellular necrosis were graded from 0 to 4 , where $0=$ none, $1=$ mild (acidophilic bodies, ballooning degeneration and/or scattered foci of hepatocellular necrosis in $<1 / 3$ of lobules or nodules), $3=$ moderate (involvement of $1 / 3-2 / 3$ of lobules or nodules), $4=$ marked (involvement of $>2 / 3$ of lobules or nodules). Category III, portal inflammation, was graded from 0 to 4 , where $0=$ no portal inflammation, $1=$ =mild (sprinkling of inflammatory cells in $<1 / 3$ of portal tracts), 3=moderate (increased inflammatory cells in $1 / 3-2 / 3$ of portal tracts), $4=$ marked (dense packing of inflammatory cells in $>2 / 3$ of portal tracts). Category IV, fibrosis, was graded from 0 to 4 , where $0=$ no fibrosis, $1=$ fibrous portal expansion, 3 =bridging fibrosis (portal-portal or portal-central linkage), 4=cirrhosis. 
Maruoka et al.

\section{References}

1. Nishimura $\mathrm{H}$, Minato $\mathrm{N}$, Nakano $\mathrm{T}$, et al. Immunological studies on PD-1 deficient mice: implication of PD-1 as a negative regulator for B cell responses. Int Immunol 1998;10:1563-1572.

2. Nishimura H, Okazaki T, Tanaka Y, et al. Autoimmune dilated cardiomyopathy in PD-1 receptor-deficient mice. Science 2001;291:319-322.

3. Shinkai Y, Rathbun G, Lam KP, et al. RAG-2-deficient mice lack mature lymphocytes owing to inability to initiate $\mathrm{V}(\mathrm{D}) \mathrm{J}$ rearrangement. Cell 1992;68:855-867.

4. Kido M, Watanabe N, Okazaki T, et al. Fatal autoimmune hepatitis induced by concurrent loss of naturally arising regulatory $\mathrm{T}$ cells and PD-1-mediated signaling. Gastroenterology 2008;135:1333-1343.

5. Aoki N, Kido M, Iwamoto S, et al. Dysregulated generation of follicular helper T cells in the spleen triggers fatal autoimmune hepatitis in mice. Gastroenterology 2011;140:1322-1333.

6. Klonowski KD, Marzo AL, Williams KJ, et al. CD8 T cell recall responses are regulated by the tissue tropism of the memory cell and pathogen. $\mathrm{J}$ Immunol 2006;177:6738-6746.

7. Muramatsu M, Kinoshita K, Fagarasan S, et al. Class switch recombination and hypermutation require activation-induced cytidine deaminase (AID), a potential RNA editing enzyme. Cell 2000;102:553-563.

8. Blobel G, Potter VR. Nuclei from rat liver: isolation method that combines purity with high yield. Science 1966;154:1662-1665.

9. Knodell RG, Ishak KG, Black WC, et al. Formulation and application of a numerical scoring system for assessing histoloical activity in asymptomatic chronic active hepatitis. Hepatology 1981;1:431-435. 
Maruoka et al.

\section{Supplementary Figure 1}

A
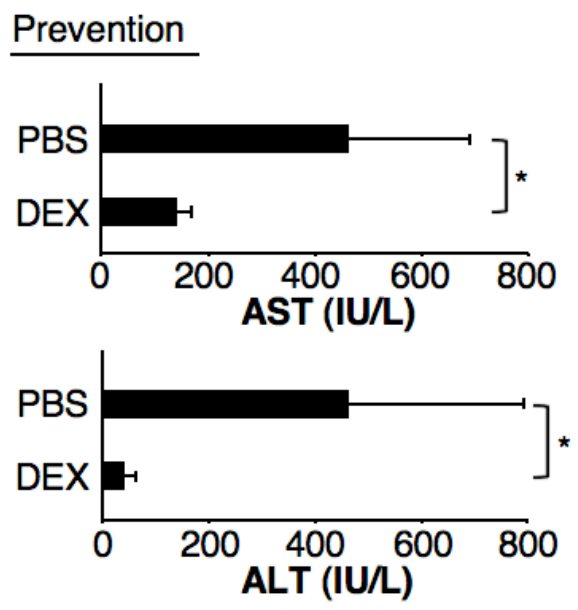

B
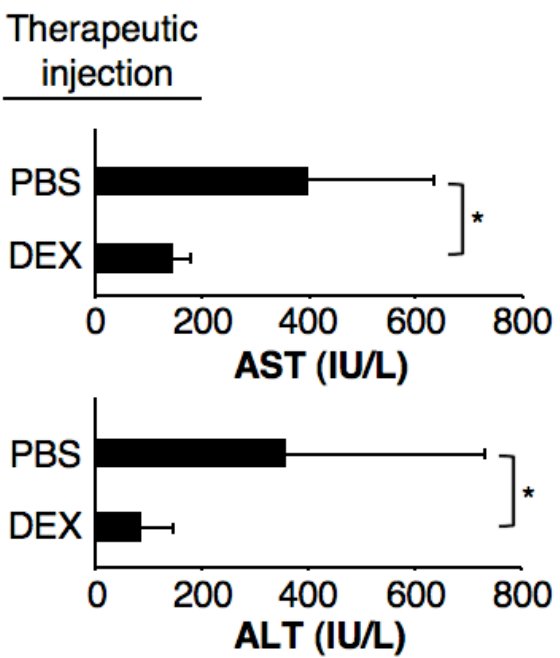

\section{Supplementary Figure 1}

Either preventive or therapeutic injection of dexamethasone (DEX) suppresses fatal AIH in BALB/C-NTX-PD-1 $1^{-/-}$mice. $(A)$ BALB/C-NTX-PD-1 $-1^{-/-}$mice at one day after thymectomy were intraperitoneally injected every other day with $1.0 \mathrm{mg} / \mathrm{kg}$ of DEX diluted in PBS $(n=5)$ or PBS alone $(n=17)$. After 13 injections, mice at four weeks of age were sacrificed, and sera were harvested. Serum levels of the liver transaminases AST and ALT. (B) NTX-PD-1 $1^{-/-}$mice at 14 days after thymectomy were intraperitoneally injected every other day with $1.0 \mathrm{mg} / \mathrm{kg}$ of DEX diluted in PBS $(n=11)$ or PBS alone $(n=13)$. After 6 injections, mice at four weeks of age were sacrificed. Serum levels of AST and ALT are shown. Bars indicate the mean of each group, and the error bars indicate SD. Asterisks indicate $\mathrm{P}<0.05$. 
Maruoka et al.

Supplementary Figure 2

A

\begin{tabular}{ccc} 
& Treatment & \\
\hline PBS & Preventive & Therapeutic \\
&
\end{tabular}

C

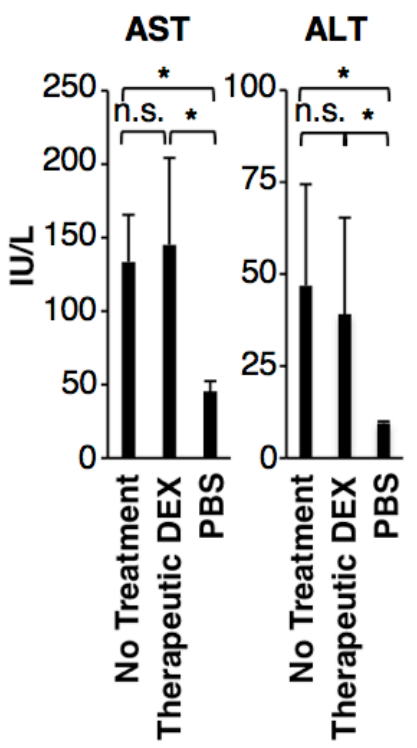

B

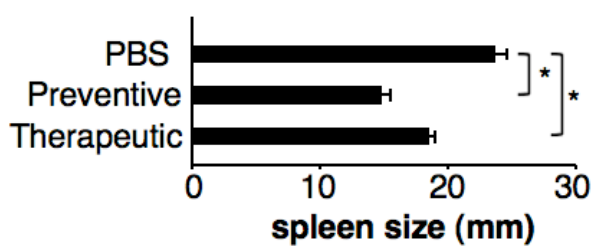

D

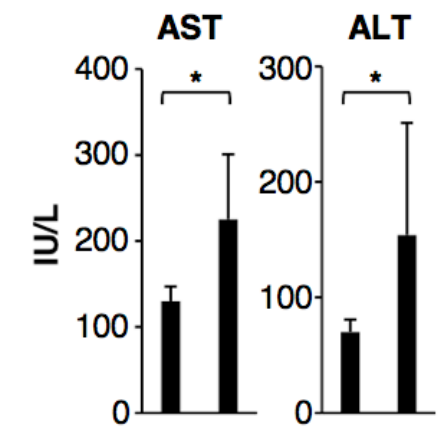

Donor $\mathrm{CD4}^{-} \mathrm{CD}^{+} \mathrm{CD4}^{-} \mathrm{CD} 4^{+}$

Spleen $\frac{\text { CDA-CDAts }}{\text { BALB/c PD1KO NTX+ }}$

\section{Supplementary Figure 2}

Therapeutic administration of DEX reduces the size of the spleen, and residual $\mathrm{CD} 4^{+} \mathrm{T}$ cells in the spleen of BALB/c-NTX-PD-1 ${ }^{-1-}$ mice can induce hepatitis. BALB/c-NTX-PD-1 ${ }^{-1-}$ mice were injected with DEX or PBS alone preventively or therapeutically, as described in Fig. 1. (A) Macroscopic view of spleen. $(B)$ Splenic sizes. $(C, D)$ Serum levels of the liver transaminases AST and ALT in recipient $\mathrm{BALB} / \mathrm{c}-\mathrm{RAG2^{-/ }}$ mice at three weeks after transfer. Total splenocytes were isolated and transferred from BALB/C-NTX-PD-1 $1^{-1-}$ mice with or without therapeutic injections of DEX $(C)$. Purified splenic $\mathrm{CD}^{+}{ }^{+}$cells or $\mathrm{CD}^{+}{ }^{+} \mathrm{T}$-cell depleted splenocytes (CD4 cells) were transferred from BALB/C-NTX-PD-1 ${ }^{-/-}$ mice therapeutically treated with $\mathrm{DEX}(D)$. Bars indicate the mean of each group, and the error bars indicate SD. Asterisks indicate $\mathrm{P}<0.05$. n. s., not significant. Scale bars, $1 \mathrm{~cm}$. 
Maruoka et al.

\section{Supplementary Figure 3}

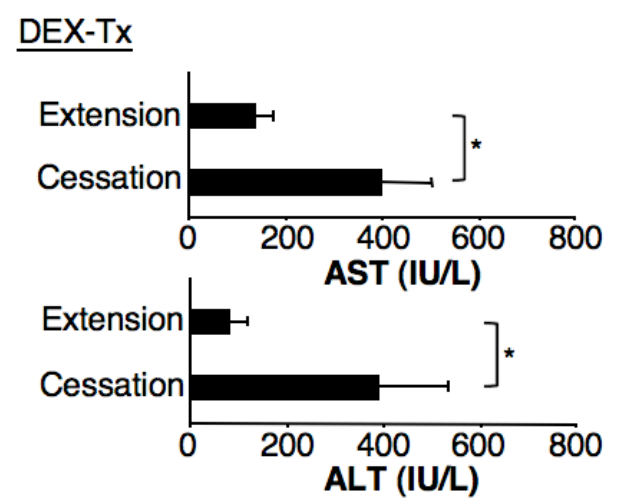

\section{Supplementary Figure 3}

Cessation of DEX therapy induces relapse of hepatitis in BALB/C-NTX-PD-1/mice. BALB/C-NTX-PD-1 ${ }^{-1-}$ mice at 14 days after thymectomy were intraperitoneally injected every other day with $1.0 \mathrm{mg} / \mathrm{kg}$ of DEX. Mice with DEX injection extended until 40 days of age (Extension, $n=7$ ) or mice with cessation of DEX injections at 4 weeks of age (Cessation, $n=10$ ) were sacrificed at 40 days of age, and sera were harvested. Serum levels of the liver transaminases AST and ALT are shown. The bars indicate the mean of each group, and the error bars indicate SD. Asterisks indicate $\mathrm{P}<0.05$.

\section{Supplementary Figure 4}
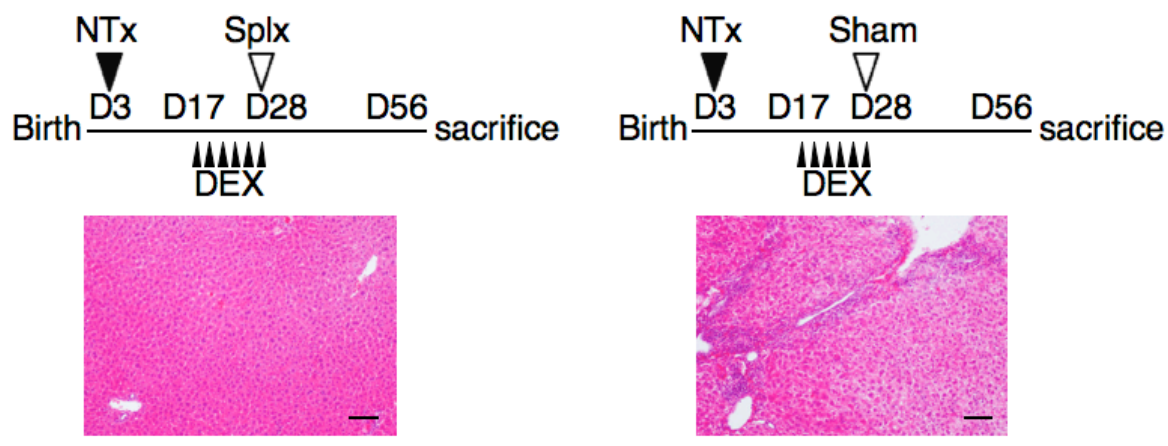

\section{Supplementary Figure 4}

Splenectomy overcomes therapeutic insufficiency of corticosteroids and induces prolonged remission of $\mathrm{AlH}$ in $\mathrm{BALB} / \mathrm{c}-\mathrm{NTX}-P D-1^{-/-}$mice. BALB/C-NTX-PD-1/mice at 14 days after thymectomy were intraperitoneally injected every other day with $1.0 \mathrm{mg} / \mathrm{kg}$ of DEX. After 6 injections, mice stopped receiving DEX injections and underwent splenectomy $(S p l x, n=3)$ or sham operation $(n=3)$ at 28 days of age. Mice at 56 days of age were sacrificed, and the livers were harvested. 
Maruoka et al.

Histological analysis of the liver from each group. Staining of the liver for hematoxylin and eosin. All scale bars, $100 \mu \mathrm{m}$.

\section{Supplementary Figure 5}

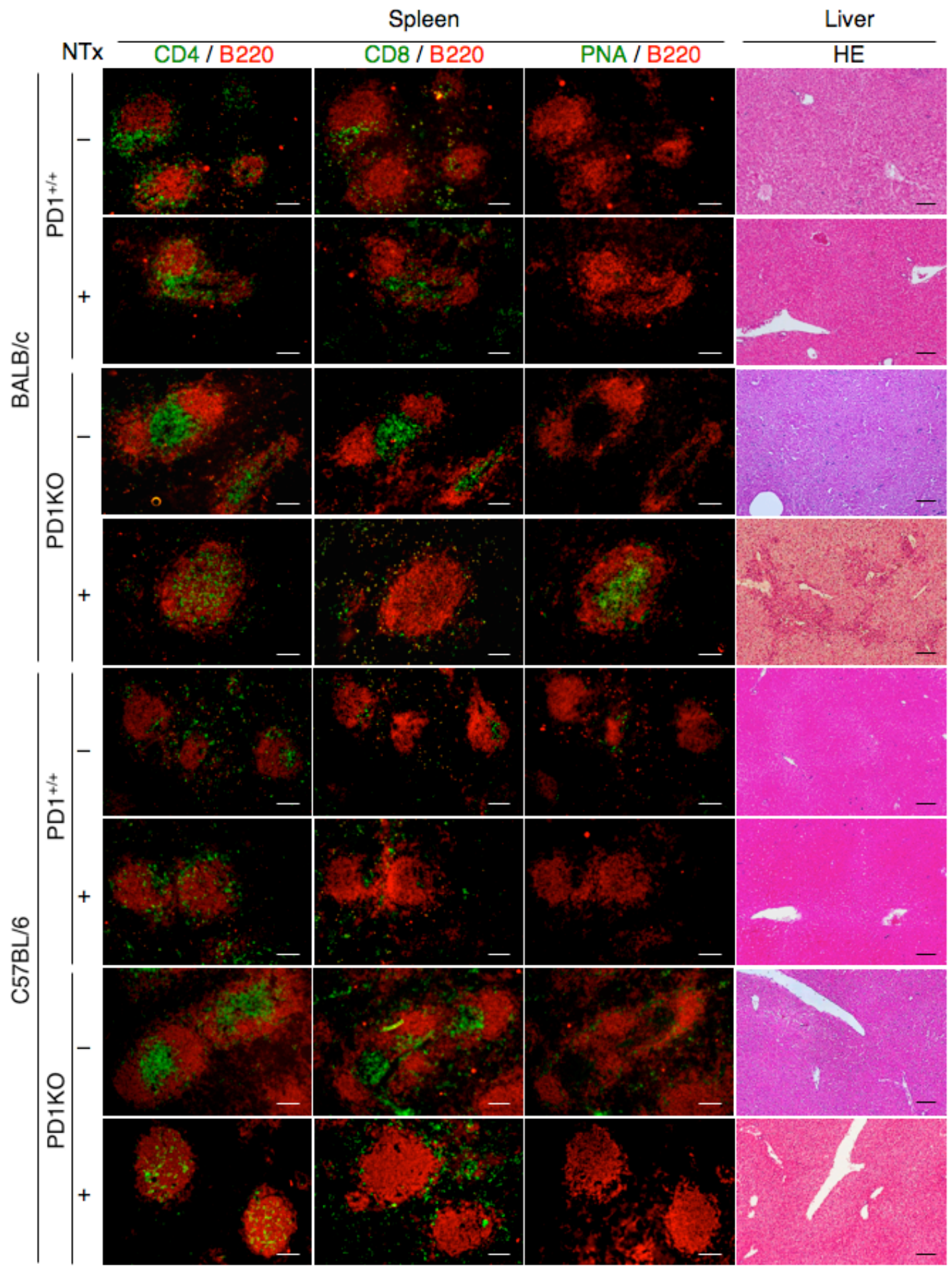


Maruoka et al.

\section{Supplementary Figure 5}

Splenic $\mathrm{CD}^{+}{ }^{+}$cells are preferentially localized within $\mathrm{B} 220^{+}$B-cell follicles in NTX $-P D-1^{-1-}$ mice at two weeks of age, whereas PNA+ germinal centers exist in $\mathrm{B} 220^{+} \mathrm{B}$-cell follicles in the spleen of $\mathrm{AlH}$-bearing $\mathrm{NTX}-P D-1^{-1-}$ mice on the $\mathrm{BALB} / \mathrm{C}$ background but in not those on the C57BL/6 background. Immunohistological staining of the spleen (left panels) and H\&E (HE) staining of the liver (right panels). The spleens and livers were from 2-week-old $P D-1^{+++}$ mice or $P D-1^{-1-}$ mice with or without NTx on the BALB/C or C57BL/6 background. The spleens were stained with FITC-conjugated anti-CD4, anti-CD8 or peanut agglutinin (PNA) (green) and biotin-labeled anti-B220 followed by Texas red-conjugated avidin (red). All scale bars, $100 \mu \mathrm{m}$.

Supplementary Figure 6

A

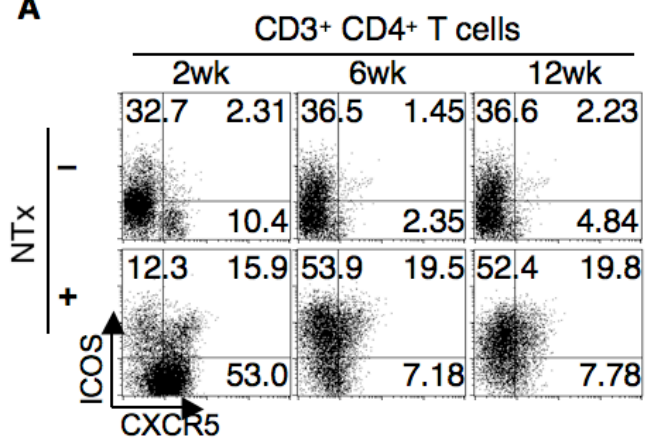

B

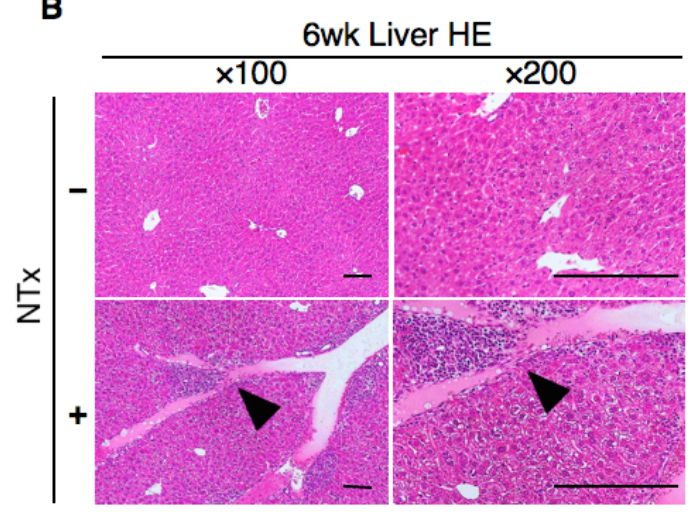

C

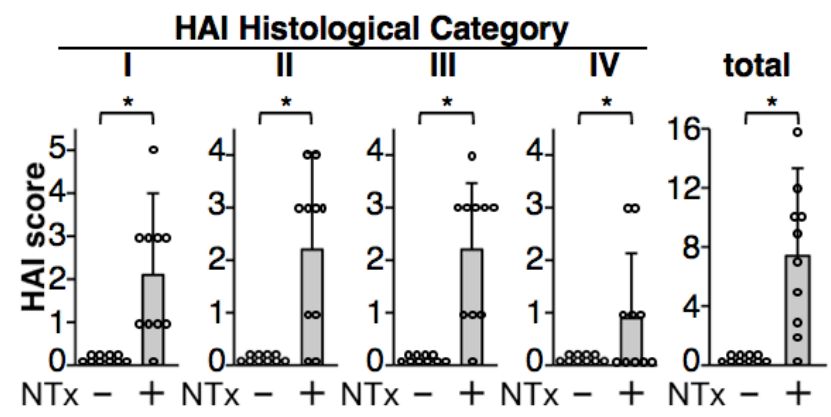

\section{Supplementary Figure 6}

Adult C57BL/6-NTX-PD-1 $1^{-/-}$mice with increased numbers of splenic $\mathrm{T}_{\mathrm{FH}}$ cells develop chronic hepatitis. $(A)$ Flow cytometric analysis of splenic CD4 ${ }^{+} \mathrm{T}$ cells in C57BL/6-PD-1 $1^{-/-}$mice with or without NTx at indicated ages. The cells were stained with FITC-anti-CXCR5, PE-anti-ICOS, APC-Cy7-anti-CD4. Numbers in plots indicate percentage of cells in each gate in the $C D 4^{+}$T-cell population. $(B)$ Histological findings from the livers of 6-week-old C57BL/6-PD-1 ${ }^{-1-}$ mice with or without NTx. In contrast to mice without NTx, those with NTx showed dense packing of inflammatory cells marked in portal branches (black arrowhead). 
Maruoka et al.

Scale bars, $100 \mu \mathrm{m}$. (C) Knodell's histological activity index (HAI) score for livers in 8-week-old C57BL/6-PD-1 ${ }^{-1-}$ mice with $(n=10)$ or without NTx $(n=10)$. HAI score is graded in four categories: I, periportal and/or bridging necrosis; II, intralobular degeneration and focal hepatocellular necrosis; III, portal inflammation; IV, fibrosis, all as described in Supplementary Methods.

\section{Supplementary Figure 7}
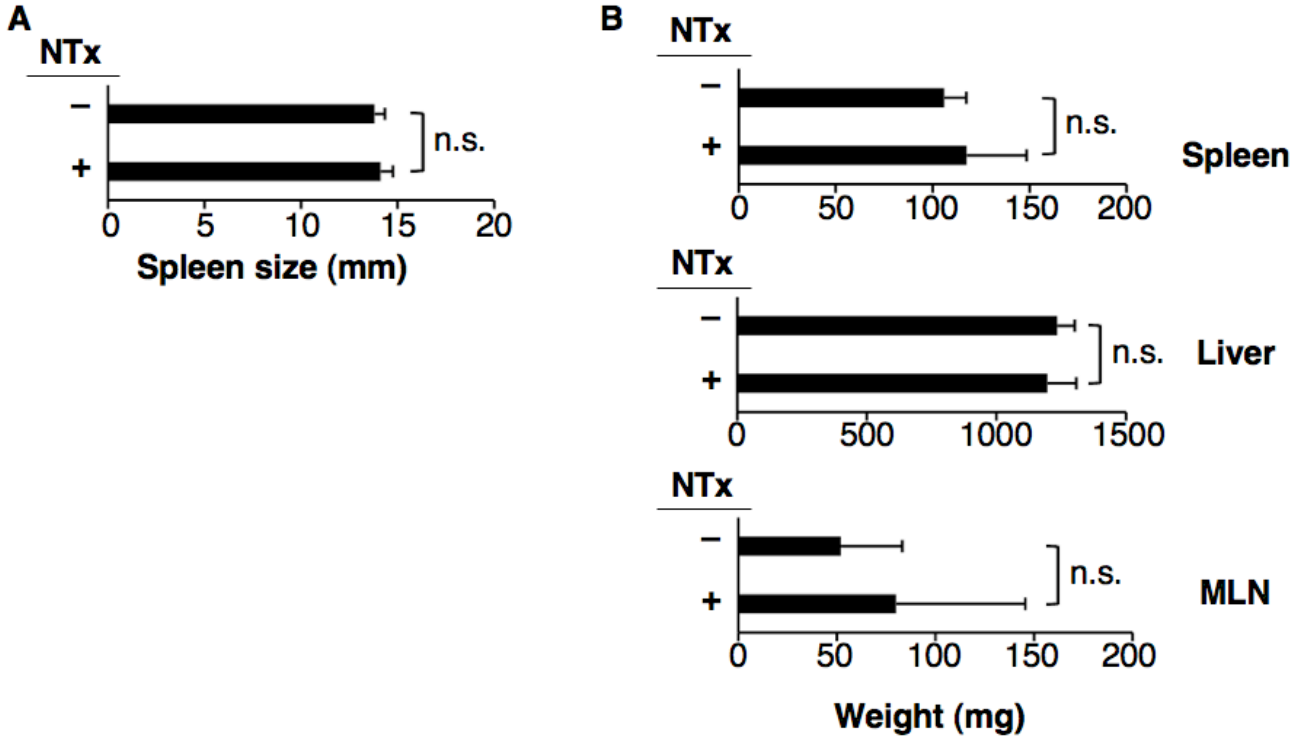

\section{Supplementary Figure 7}

Adult C57BL/6-NTX-PD-1 $1^{-/}$mice do not show obvious splenomegaly. Splenic sizes $(A)$ and weights of the spleen, liver, and mesenteric lymph node (MLN) (B) in 12-week-old C57BL/6-PD-1 $1^{-1-}$ mice with or without NTx. Bars indicate the mean of each group, and the error bars indicate SD. n.s., not significant. 
Maruoka et al.

Supplementary Figure 8

A

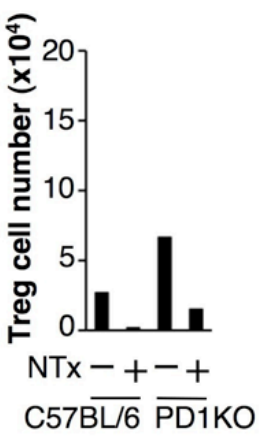

B

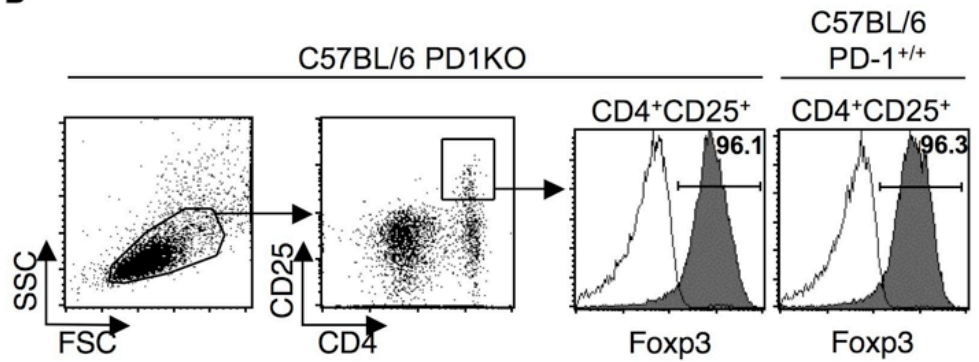

C

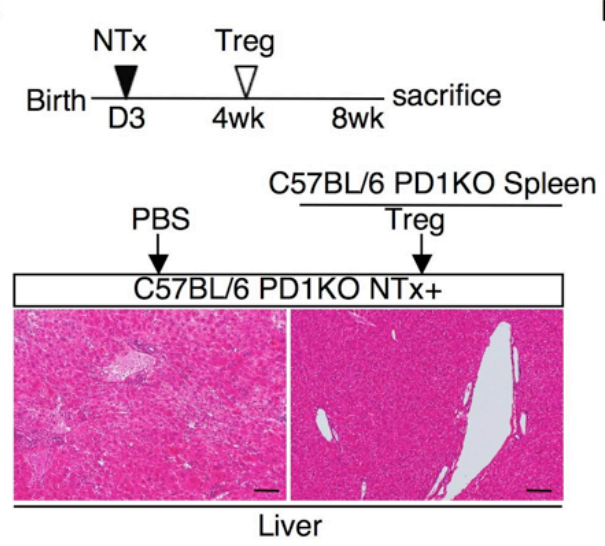

D

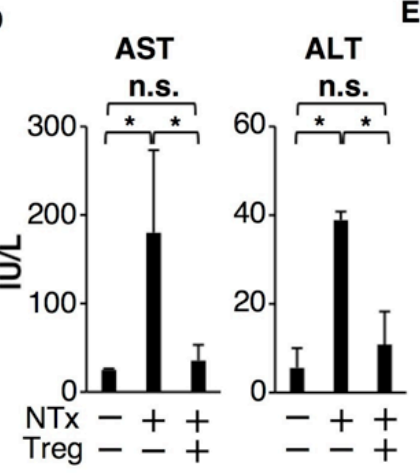

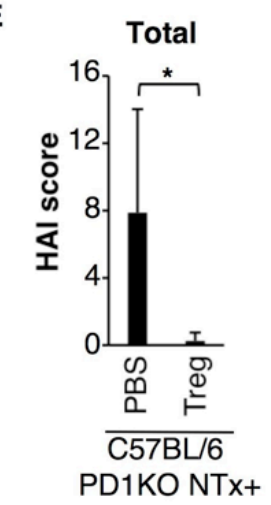

\section{Supplementary Figure 8}

Transfer of regulatory $T$ cells (Tregs) has therapeutic efficacy for chronic AlH in C57BL/6-NTX-PD-1 ${ }^{-1-}$ mice. (A) Flow cytometric analysis of Tregs in the liver from the indicated mice at 6 weeks of age. The cells were stained with FITC-anti-CD4, PE-anti-CD3, APC-anti-CD25. Numbers of $\mathrm{CD}^{+} \mathrm{CD} 4^{+} \mathrm{CD} 25^{+}$ Tregs were calculated by (percentage of the cells in the cell types) $X$ (number of viable cells). Data shown are one of three separate experiments. (B) Flow cytometric analysis of $\mathrm{CD} 4+\mathrm{CD} 25+\mathrm{T}$ cells in the spleen from the 8-week-old C57BL/6-PD-1 $1^{-1-}$ or $P D-1^{+++}$mice. The cells were isolated from spleen and stained with FITC-anti-CD4, APC-anti-CD25, and PE-anti-Foxp3. Filled histograms represent staining of CD4+CD25+ $T$ cells with Foxp3; open histograms represent the isotype control. Data represent one of five experiments. Numbers in histograms indicate percentages of $\mathrm{Foxp}^{+}$cells in a viable CD4+CD25+ T cells. (C-E) For Treg transfer, $1 \times 10^{6}$ of Tregs were prepared from 8-week-old C57BL/6-PD-1 ${ }^{-1 /}$ mice. Four-week-old C57BL/6-NTX-PD-1/- mice were intravenously injected with $1 \times 10^{6}$ of Tregs $(n=5)$ or PBS $(n=5)$. Recipient mice were analyzed at 8 weeks of age. (C) Histological findings of the liver. Scale bars, $100 \mu \mathrm{m}$. (D) Serum levels of the liver transaminases, aspartate 
Maruoka et al.

aminotransferase (AST), and alanine aminotransferase (ALT). (E) Knodell's histological activity index ( $\mathrm{HAl})$ score. Bars indicate the mean of each group, and the error bars indicate SD. Asterisks indicate $\mathrm{P}<0.05$. n.s., not significant.

\section{Supplementary Figure 9}

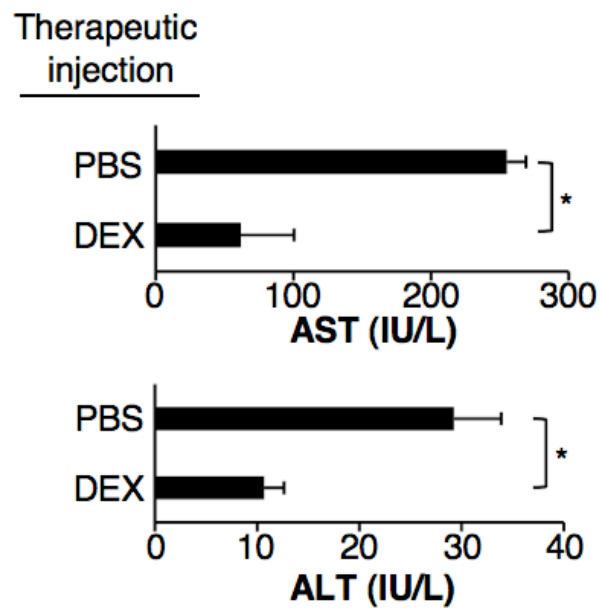

\section{Supplementary Figure 9}

Therapeutic injections of DEX suppress chronic AlH in C57BL/6-NTX-PD-1 ${ }^{-/}$ mice. Intraperitoneal injections of DEX $(n=5)$ or PBS $(n=5)$ were started at 4 weeks of age in C57BL/6-NTX-PD-1/- mice. After 14 injections every other day at eight weeks of age, mice were sacrificed and examined. Serum levels of the liver transaminases AST and ALT are shown. Bars indicate the mean of each group, and the error bars indicate SD. Asterisks indicate $\mathrm{P}<0.05$. 
Maruoka et al.

\section{Supplementary Figure 10}

A

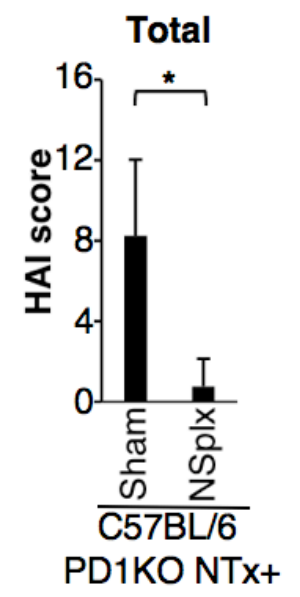

C

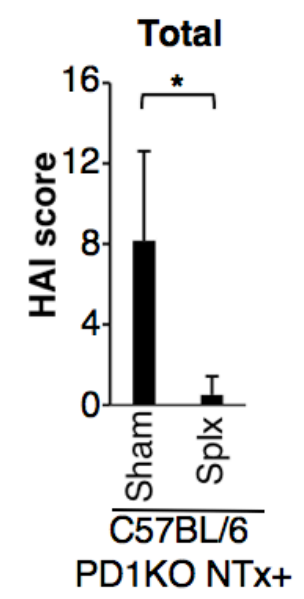

B

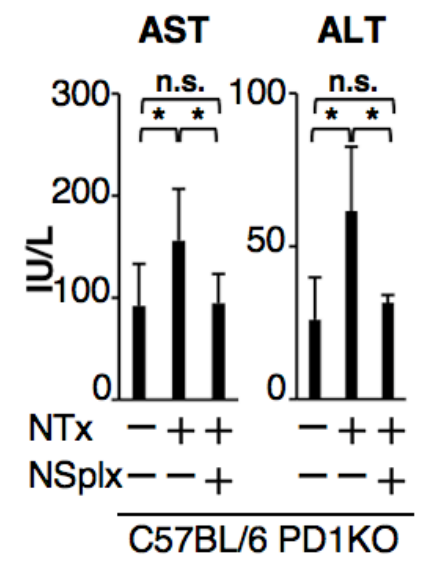

D

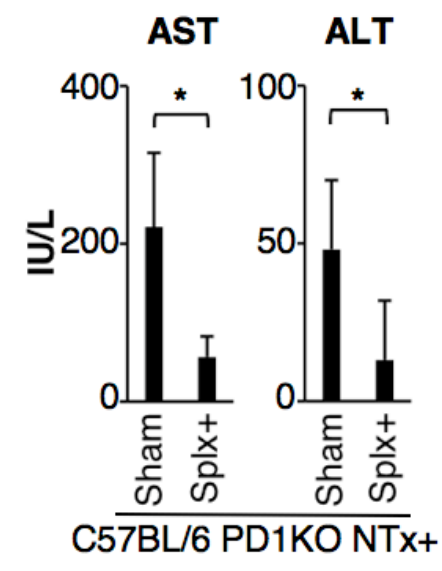

\section{Supplementary Figure 10}

The spleen is the induction site of chronic AlH in C57BL/6-NTX-PD-1/- mice, and splenectomy suppresses chronic AlH. $(A, B)$ C57BL/6-NTX-PD-1 ${ }^{-1-}$ mice underwent a splenectomy (NSplx, $n=5)$ or a sham operation $(n=5)$ at one day after NTx, and were analyzed at 8 weeks of age. $(C, D)$ Four-week-old C57BL/6-NTX-PD-1 ${ }^{-/-}$mice underwent a splenectomy (Splx, $n=5$ ) or a sham operation $(n=5)$ and were analyzed at 8 weeks of age. Total HAl scores for livers as described in Supplementary Methods ( $A$ and $C$ ). Serum levels of the liver transaminase, AST and ALT ( $B$ and $D)$. Bars indicate the mean of each group, and horizontal short bars indicate SD. Asterisks indicate $\mathrm{P}<0.05$. n.s., not significant. 
Maruoka et al.

\section{Supplementary Table 1}

Incidence of autoimmunity in various organs of C57BL/6 PD1KO mice with or without NTX

\begin{tabular}{|c|c|c|c|c|c|c|c|c|}
\hline \multirow{2}{*}{$\begin{array}{c}\text { Mice } \\
\text { Age (Month) } \\
\text { (total number) }\end{array}$} & \multicolumn{4}{|c|}{ C57BL/6 PD1KO NTx+ } & \multicolumn{4}{|c|}{ C57BL/6 PD1KO NTx- } \\
\hline & $\frac{\sim 1 \mathrm{M}}{(\mathrm{n}=14)}$ & $\begin{array}{c}1 \sim 2 M \\
(n=19) \\
\end{array}$ & $\begin{array}{c}2 \sim 3 M \\
(n=15) \\
\end{array}$ & $\frac{3 \mathrm{M} \sim}{(\mathrm{n}=12)}$ & $\begin{array}{c}\sim 1 \mathrm{M} \\
(\mathrm{n}=12)\end{array}$ & $\begin{array}{c}1 \sim 2 \mathrm{M} \\
(\mathrm{n}=15)\end{array}$ & $\begin{array}{c}2 \sim 3 M \\
(n=16)\end{array}$ & $\frac{3 \mathrm{M} \sim}{(\mathrm{n}=16)}$ \\
\hline Hepatitis & $6(42.9 \%)$ & $16(84.2 \%) 1$ & $(100 \%)$ & $12(100 \%)$ & $0(0 \%)$ & $0(0 \%)$ & $0(0 \%)$ & $2(12.5 \%)$ \\
\hline Sialadenitis & $0(0 \%)$ & $9(47.4 \%)$ & $5(33.3 \%)$ & $4(33.3 \%)$ & $0(0 \%)$ & $0(0 \%)$ & $0(0 \%)$ & $0(0 \%)$ \\
\hline Pan & $0(0 \%)$ & 3\%) & $4(2$ & $2(16.7$ & $0(0 \%)$ & $0(0$ & $\%)$ & $0(0 \%)$ \\
\hline Myo & $0(0 \%)$ & $8 \%)$ & $2(1$ & $2(16.7 \%)$ & $0(0 \%)$ & $0(0$ & $\%)$ & $0(0 \%)$ \\
\hline & $0(0 \%)$ & $2(10.5 \%)$ & $2(13.3 \%)$ & $2(16.7 \%)$ & $0(0 \%)$ & $0(0 \%)$ & $0(0 \%)$ & $0(0 \%)$ \\
\hline Gastritis & $0(0 \%)$ & $0(0 \%)$ & $0(0 \%)$ & $1(8.3 \%)$ & $0(0 \%)$ & $0(0 \%)$ & $0(0 \%)$ & $0(0 \%)$ \\
\hline Enteritis & $0(0 \%)$ & $0(0 \%)$ & $0(0 \%)$ & $0(0 \%)$ & $0(0 \%)$ & $0(0 \%)$ & $0(0 \%)$ & $0(0 \%)$ \\
\hline Pneumonitis & $0(0 \%)$ & $0(0 \%)$ & $0(0 \%)$ & $0(0 \%)$ & $0(0 \%)$ & $0(0 \%)$ & $0(0 \%)$ & $0(0 \%)$ \\
\hline
\end{tabular}

The tissues of various organs in C57BL/6 PD1KO mice with or without NTx at the indicated ages ( $n=12 \sim 19$ in each group) were evaluated histologically. Incidence was determined by inflammation characterized by slight infiltration of mononuclear cells in the organs by lymphocytes.

\section{Supplementary Table 2}

Survival rate with or without splenectomy

\begin{tabular}{ccc}
\hline Mice & \multicolumn{2}{c}{ C57BL/6 PD1 $1^{-1}$ NTx } \\
\cline { 2 - 3 } $\begin{array}{c}\text { Sple 6 week } \\
\text { Total number }\end{array}$ & + & - \\
\hline $\begin{array}{c}\text { Survival rate } \\
\text { at 20 weeks of age }\end{array}$ & $\mathrm{n}=8$ & $\mathrm{n}=16$ \\
\hline
\end{tabular}

